\title{
A transactive energy modelling and assessment framework for demand response business cases in smart distributed multi-energy systems
}

DOI:

10.1016/j.energy.2018.02.089

\section{Document Version}

Accepted author manuscript

Link to publication record in Manchester Research Explorer

Citation for published version (APA):

Good, N., Martinez Cesena, E. A., Heltorp, C., \& Mancarella, P. (2018). A transactive energy modelling and assessment framework for demand response business cases in smart distributed multi-energy systems. Energy. https://doi.org/10.1016/j.energy.2018.02.089

Published in:

Energy

\section{Citing this paper}

Please note that where the full-text provided on Manchester Research Explorer is the Author Accepted Manuscript or Proof version this may differ from the final Published version. If citing, it is advised that you check and use the publisher's definitive version.

\section{General rights}

Copyright and moral rights for the publications made accessible in the Research Explorer are retained by the authors and/or other copyright owners and it is a condition of accessing publications that users recognise and abide by the legal requirements associated with these rights.

\section{Takedown policy}

If you believe that this document breaches copyright please refer to the University of Manchester's Takedown Procedures [http://man.ac.uk/04Y6Bo] or contact uml.scholarlycommunications@manchester.ac.uk providing relevant details, so we can investigate your claim.

\section{OPEN ACCESS}




\title{
1 A transactive energy modelling and assessment framework for demand \\ 3 response business cases in smart 4 distributed multi-energy systems
}

Nicholas Good ${ }^{1} *$, Eduardo A. Martínez Ceseña ${ }^{1}$, Christopher Heltorp ${ }^{1}$, and Pierluigi Mancarella ${ }^{1,2}$

${ }^{1}$ School of Electrical and Electronic Engineering, The University of Manchester, Ferranti Building, Manchester, M13 9PL, UK; emails: \{nicholas.good, eduardo.martinezcesena, p.mancarella\}@manchester.ac.uk, christopher_heltorp@hotmail.com

${ }^{2}$ Department of Electrical and Electronic Engineering, The University of Melbourne, Parkville, Victoria, 3010, Australia; email: pierluigi.mancarella@unimelb.edu.au

*Corresponding author Tel: +44 (0)161 3064807

\section{Highlights}

- Transactive energy modelling and assessment for demand response business cases

- Flexible and scalable modelling of aggregation for distributed multi-energy systems

- Includes a novel, modular and extensible transactive energy value mapping model

- Consumer/retailer-aggregator profit sharing model introduced

- Demonstrated on a real case study of a smart district

\begin{abstract}
The energy trilemma, together with energy system liberalisation and development of smart grid technologies, are increasing interest in and the potential of distributed multi-energy systems (DMES), for instance from districts or communities, to provide demand response (DR). However modelling and assessment of such systems is not straightforward given the complex physical and commercial aspects, including the effect of aggregation and relationships between retailers/aggregators and the districts in which DR resources are situated. Given this motivation, this paper introduces a novel and powerful 'transactive energy' modelling and assessment framework for DMES. The framework includes: a DMES stochastic optimisation model with a flexible and scalable approach for modelling aggregation useful for both technical and economic analysis; a modular and extensible value mapping methodology for identifying transactive energy price signals and cash flows for different energy system actors; a profit sharing model; and an economic assessment model based on fundamental cost-benefit analysis. The framework is illustrated through analysis of DR business cases on a real district in France. Possible extensions of the transactive energy value mapping approach to upstream and downstream activities and to different energy sectors, as well as the advantages of using the framework in regulatory and policy design, are discussed.
\end{abstract}


1 Key words: business cases, demand response, multi-energy systems, transactive energy,

2 smart grid, smart districts

\section{$3 \quad$ Nomenclature}

$4 \quad$ Acronyms

BRE Balancing responsible entity

CBA Cost benefit analysis

CM Capacity market

DMES Distributed multi-energy system

DNCM Distribution network constraint management

DR Demand response

DUoS Distribution use-of-system

EDNO Electricity distribution network operator

EHP Electric heat pump

ESO Environmental and social obligation

ETSO Electricity transmission system operator

GCP Grid connection point

ICT Information and communication technology

IRR Internal rate of return

MIP Minimisation imbalance penalty

NPV Net present value

OPWM Optimised purchase on the wholesale market

RAD Retailer-aggregator-district

RES Renewable energy sources

TES Thermal energy store

UoS Use-of-system

VAT Value added tax

$5 \quad$ Mappings

$6 \boldsymbol{M}_{\boldsymbol{C}, \boldsymbol{R}} \quad$ District to role map

$7 \quad \boldsymbol{M}_{\boldsymbol{D}, \boldsymbol{T}} \quad$ Demand to TES map

$8 \boldsymbol{M}_{G, C} \quad$ GCP to commercial agent map

$9 \boldsymbol{M}_{\boldsymbol{G}, \boldsymbol{N}} \quad$ GCP to local network map

$10 \boldsymbol{M}_{\boldsymbol{H}, \boldsymbol{P}} \quad$ Electricity conversion, generation and storage to premises map

$11 \boldsymbol{M}_{P, G} \quad$ Premises to GCP map

$12 \quad M_{R, A} \quad$ Role to actor map

$13 \boldsymbol{M}_{\boldsymbol{T}, \boldsymbol{H}} \quad$ TES to heat generator map

14 Parameters

$15 C_{s, i}^{\text {call }}$ Capacity call indicator (binary)

$16 C_{i}^{\text {window }}$ Capacity window indicator (binary)

17 J Matrix of ones

$18 N_{C} \quad$ Number of commercial agents

$19 N_{D} \quad$ Number of demand centres

$20 N_{G} \quad$ Number of GCPs

$21 \quad N_{H} \quad$ Number of energy converters

$22 N_{I} \quad$ Number of settlement periods

$23 \quad N_{N} \quad$ Number of local energy networks

$24 \quad N_{P} \quad$ Number of premises

$25 N_{S} \quad$ Number of scenarios 
$1 \quad N_{T} \quad$ Number of storage

$2 p_{s} \quad$ Scenario probability

$3 t \quad$ Length of time-step (hours)

$4 \quad \chi(g)_{i, g}^{-}$GCP import price ( $\mathrm{f} / \mathrm{kWh}$ )

$5 \quad \chi(g)_{i, g}^{+}$GCP export price ( $\left.\mathrm{f} / \mathrm{kWh}\right)$

$6 \quad \chi(p)_{i, p}^{-}$Premises import price $(\mathrm{f} / \mathrm{kWh})$

$7 \quad \chi(p)_{i, p}^{+}$Premises import price ( $(\mathrm{k} / \mathrm{kWh})$

$8 \quad \gamma_{n} \quad$ Network limit

$9 \lambda_{i}^{-} \quad$ Day-ahead import price $(\mathrm{f} / \mathrm{kWh})$

$10 \lambda_{i}^{+} \quad$ Day-ahead export price $(\mathrm{f} / \mathrm{kWh})$

$11 \mu_{s, i}^{-} \quad$ Imbalance import price $(\mathrm{f} / \mathrm{kWh})$

$12 \mu_{s, i}^{+} \quad$ Imbalance export price ( $\mathrm{f} / \mathrm{kWh}$ )

$13 \omega_{s, i} \quad$ Capacity call price $(\mathrm{f} / \mathrm{kW})$

$14 \pi_{s, i} \quad$ Capacity availability price $(\mathrm{f} / \mathrm{kW})$

15 Variables

Actor cash flow

D

District cash flow

Vector of demand

G

GCP import/export

$\boldsymbol{R}$

Role cash flow

$P$

Premises import/export

$T$

Vector of TES heat outflow

$\boldsymbol{U}$

$B C R_{\text {case }}^{D}$

Matrix of TES-demand flows

District's share of additional revenue from considered business case

$B C R_{\text {case }}^{R A}$

Retailer-aggregator's share of additional revenue from considered business case

$D_{i, c}^{-}$

Day-ahead electricity import (kWh)

$D_{i, c}^{+}$

Day-ahead electricity export (kWh)

Imbalance electricity import (kWh)

Imbalance electricity export (kWh)

Capacity commitment (kW)

GCP electricity import (kWh)

$E(g)_{s, i, g}^{-}$

$E(g)_{s, i, g}^{+}$

GCP electricity export ( $k W h)$

$33 E(p)_{s, i, p}^{-}$

Premises electricity import ( $\mathrm{kWh}$ )

$34 E(p)_{s, i, p}^{+}$

35 Ecost $t_{\text {base }}^{\text {RAD }}$

Premises electricity export ( $\mathrm{kWh}$ )

$36 \quad$ Elec $_{\text {case }}$

Annual RAD cost of electricity

$37 \quad P M$

38 Rev case

Electricity consumption for the given case

Required retailer annual profit margin

Annual district revenue

Annual retailer-aggregator revenue

Service fee

$40 \quad S F$

Electricity tariff

\section{Introduction}

Legislative efforts to increase the sustainability of energy systems (by reducing emissions), combined with 
(utility-scale and distributed) and electric heating and transport are increasing. These trends produce two countervailing further trends, i.e., increased demand for flexibility, but also an increase in technologies capable of supplying flexibility. Demand for flexibility is expected to rise as network/system issues increase. More RES will increase variability and uncertainty in system operation, thereby increasing the requirement for balancing services; at the same time, the business cases for traditional providers of such services (flexible generation) will be eroded [1,2]. Further, increased and bi-directional electricity flows at the distribution level can produce thermal and voltage issues at the district level $[3,4]$. At the same time, greater electrification of heating and transport as well as increased penetration of smart grid technologies in local RES (e.g., photovoltaic inverters) will contribute to a trend for distributed multi-energy systems (DMES) to potentially provide flexibility via demand response (DR). DR from DMES can be understood as being derived from several factors, namely, storage, substitution, curtailment and power factor correction [5,6]. Utilising a multi-energy view [7], storage may be of electricity, or some derived energy vector/product, such as heat, and substitution may be of one fuel for another (e.g., electricity for fuel oil), to produce the same final product (e.g., mobility). Curtailment may relate to some energy service, such as thermal comfort [8,9], whilst power factor correction (of a building, or a district) may be enacted by some power electronic interface (e.g., from a battery or solar photovoltaic connection) [6]. Clearly increased electrification of transport and heating, together with developments in information and communication technology (ICT) and exploitation of multi-energy resources will result in more opportunities to provide DR from DMES [6,10-13].

Although flexibility from these DMES (e.g., districts or community based energy systems) may be considered more attractive than other sources of flexibility (given their location on distribution networks, which introduces the possibility of providing local services) there are multiple and various barriers facing such new players in the developing "smart grid" [14,15]. Focusing on districts (which are a special case of DMES and which, when augmented with appropriate technologies, may be considered a component of larger "smart" constructs, such as cities [7]) a key barrier is the lack of appropriate techno-economic models. Modelling and assessment of DR from such "smart energy districts" requires a holistic framework, covering both physical and commercial aspects. On the physical side, models must capture the multiple sources of (multi-energy) flexibility which can be exploited $[8,16]$. Given the importance of physical and virtual (commercial) aggregation with respect to heat, as well as gas and electricity, the framework should allow for modelling of various permutations of aggregation arrangements. Given the complexity of optimisation problem formulation, especially if a stochastic optimisation is being employed with many sources of storage, such a method should be flexible and scalable. On the commercial side there is then a requirement for methods which can breakdown the complexity of DR business cases (covering energy, capacity, or flexibility services [17]) and highly networked energy systems. Such complexity may be even more significant if costs related to DR exercise need to be shared [18-20]. Further, connections can be expected to increase between markets for substitutable energy vectors and fuels in a multi-energy context [7,21-23]. Understanding and modelling this complexity has been identified as a priority by both regulatory bodies and academics [24-26].

Another necessary feature for a smart energy district modelling and assessment framework is the ability to model methods for sharing the benefits of flexibility exploitation between district consumers and their commercial partner (e.g., aggregator or retailer). In the existing literature a qualitative examination of how benefits from 'co-provision' (by consumers, as well as energy retailers/energy service companies) of energy or energy services may be shared between relevant actors has been undertaken in $[27,28]$. For smart districts the provision of flexibility services to upstream parties must also be considered. In this regard, theoretical and practical attention has been given to methods for controlling/coordinating prosumers, ranging from direct load control, to coordination via price signals (from national and local energy markets) [29,30]. Some of these approaches (i.e., game theory based approaches) consider how benefits should be shared amongst consumers and (in some cases) an aggregator party [29]. These approaches draw on the rich field of game theory [31] and can ensure a 'fair' distribution of benefits. However, this comes at the price of great complexity and requires significant communication and computation capabilities within the district. Detailing of further quantitative 
methods for sharing benefits from exploitation of flexibility will therefore be beneficial. This is particularly true if consumers do not wish to adopt the technology required for them to act as the autonomous intelligent agents required for game theoretic approaches. Our work thus proposes a novel approach that bridges the existing gaps while at the same time being practical and of straightforward applicability without adding technology and communication complexity.

Thus there is clearly a need for more quantitative methods for sharing benefits of flexibility exploitation between DR providers (consumers) and their commercial agents. Such methods warrant consideration given the fundamentally different nature of flexibility exploitation business cases to energy service provision business cases, as the former may, for example, often increase energy consumption, as flexibility is employed to import and store energy at lower price periods, incurring storage losses (see Section 4.3).

In this paper, addressing the deficits identified above modelling and assessment framework for smart DMES, with specific application to the particularly important case of smart districts, is presented. The framework follows a transactive energy based approach. Following the definition of the GridWise Architectural Council, we define transactive energy as "a set of economic and control mechanisms that allow the dynamic balance of supply and demand across the entire electrical infrastructure using value as a key operational parameter" [32]. The approach is ideally suited given that smart DMES are subject to multiple markets/mechanisms. Particular contributions are:

- A proposed aggregation modelling methodology which, together with previously presented stochastic, physical models can capture and exploit distributed energy flexibility to provide multiple services. This method builds on the electricity network and commercial aspects of aggregation presented in [33] to include multi-energy conversion, storage and demand.

- A novel, modular and extensible value mapping methodology which can mitigate complexity by clearly defining interactions between actors along the transactive energy value chain.

- New methods for sharing the benefits of distributed energy flexibility exploitation between DR providers and their commercial agents.

In the remainder of this paper, Section 2 introduces the modelling and assessment framework for DMES and in particular smart energy districts, including the district optimisation model, value mapping model and profit sharing model. Section 3 introduces a case study, of a district in the French system, on which the framework can be demonstrated, for various business cases. Section 4 presents the results of the case study. Section 5 concludes and highlights future avenues of research.

\section{Transactive energy modelling and assessment framework}

The transactive energy modelling and assessment framework proposed here is made up of several models. The framework, together with the main inputs to each component model, is shown in Figure 1, and is composed of the following components:

- DMES aggregation and multi-service optimisation model, exemplified for the sake of clarity on a district: The model utilises the physical energy/reserve optimisation model detailed in $[8,16]^{1}$ and the aggregation modelling concepts detailed in [33]. The model utilises energy demand profiles, weather information, wholesale energy and other services' prices (as perceived by the retailer/aggregator, see Section 3.2, and which drive system optimization in a transactive way), and the physical parameters of multi-energy conversion and storage devices (which define the overall technical flexibility features of the district) to calculate the annual energy and cash flows from following particular business cases.

\footnotetext{
${ }^{1}$ However, it is worth highlighting that any other price driven optimization model that considers different services could be used, as the framework is generally applicable and is not dependent on the employment of any specific optimization model.
} 
Mappings are introduced and employed to provide a flexible means of modelling various physical and virtual aggregation scenarios (thus potentially abstracting from a physical district).

- Value mapping model: The developed value mapping model synthesizes and reduces the complexity of the energy system by identifying individual roles and actors, and specifying the interactions between actors as transactive exchanges [34]. This allows all relevant price signals to be distinguished, and enables the impact of any business case to be clearly mapped.

- Profit sharing model: The profit sharing model serves to distribute business case benefits and costs between the district and the district's commercial agent. Two examples of profit sharing methods are given here, though any appropriate method may be included.

- Economic assessment model: The economic assessment model produces the selected cost benefit analysis (CBA) metrics, to measure the attractiveness of any business case, for the lead actor.

As detailed in Figure 1 the model produces annual energy and cash flows given various demand, device and environmental parameters and prices for wholesale energy and other services. These are fed into the value mapping model, which enables the effect of business cases on different actors to be quantified, and to the profit sharing model, which determines how profit should be shared between the DMES under study and a retailer-aggregator, through determination of relevant energy retail tariffs. The economic assessment model is fed from the profit sharing model to produce various CBA metrics. It should be noted that the framework is modular and various components of the framework can be used in isolation.

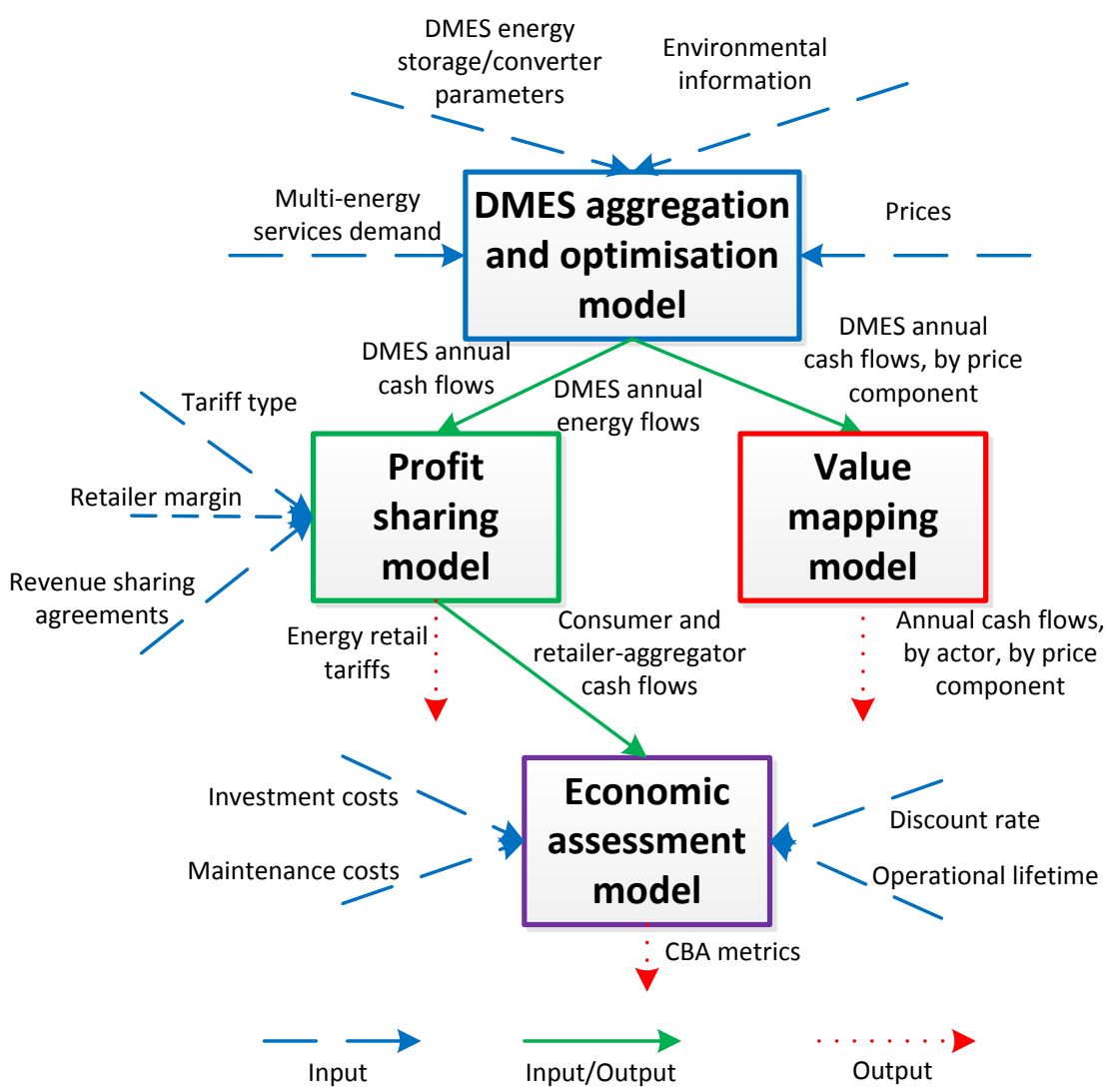

Figure 1: Illustration of the proposed transactive energy modelling and assessment framework

\subsection{DMES model: physical/virtual aggregation and multi-service optimisation}

The first step in the DMES modelling proposed here consists of building a mathematical representation of aggregation. More specifically, the definition of the relationships between the physical and commercial aspects of the specific DMES through the use of multiple mappings is a key feature of both any underlying 
optimisation model as well as the overall techno-economic assessment illustrated here. Following the commercial agent/grid connection point (GCP)/premises distinction introduced in [33] the DMES model presented here extends that concept to consider the physical as well as commercial aspects of DMES. As demonstrated in Figure 2, for electricity and heat, relationships between the various physical and commercial aspects are dictated by the different mapping matrices. With respect to the commercial aspects this is a generalisation of the approach taken in [33] where only many-to-one or many-to-many mappings were considered. With respect to the physical aspects, the framework introduced here explicitly features multienergy demand, multi-energy storage and conversion devices. Heat network connections within the DMES are modelled, in a simplified way (without considering network dynamics and constraints), through the mappings between conversion, storage and demand. The local electricity network is modelled (again in a simplified way, considering public or private ownership of local electricity networks) by the mapping between GCPs and 'networks'. Gas is another vector often relevant, but not shown here for brevity.

Figure 2 shows how the mappings relate different aspects of the DMES. For brevity the mappings are not distinguished by energy vector, though in practice each energy vector may have a different set of maps. In Figure $2 \boldsymbol{M}_{\boldsymbol{D}, \boldsymbol{T}}$ maps demand to storage, $\boldsymbol{M}_{\boldsymbol{T}, \boldsymbol{H}}$ maps storage to conversion, $\boldsymbol{M}_{\boldsymbol{H}, \boldsymbol{P}}$ maps conversion to premises, $\boldsymbol{M}_{\boldsymbol{P}, \boldsymbol{G}}$ maps premises to GCPs, and $\boldsymbol{M}_{\boldsymbol{G}, \boldsymbol{C}}$ and $\boldsymbol{M}_{\boldsymbol{G}, \boldsymbol{N}}$ map GCPs to commercial agents and local networks, respectively. In the aggregation and optimisation model these matrices are used in two ways, dependent on whether the relationship between aspects is exclusive or not. Mappings $\boldsymbol{M}_{\boldsymbol{D}, \boldsymbol{T}}$ and $\boldsymbol{M}_{\boldsymbol{T}, \boldsymbol{H}}$ define non-exclusive relationships. This allows, for example, an electricity-heat converter connected to a heat network to supply many thermal energy stores (TES), and a TES to supply many demands. Considering the relationship between demand and storage, equations (1) and (2) define this relationship in a form suitable for incorporation into an optimisation model. In these equations $\boldsymbol{J}$ is a matrix of ones, $\boldsymbol{D}$ is the vector of demand, $\boldsymbol{T}$ is the vector of storage to demand energy flow and $\boldsymbol{U}$ is an $\mathrm{N}_{\mathrm{D}} \mathrm{xN}$ 至atrix of flows between each storage and each demand (which are variables in the optimisation model). Similar equations can define the relationships between storage and the conversion-storage energy flow.

$$
\begin{gathered}
\boldsymbol{D}=\left(\boldsymbol{M}_{\boldsymbol{D}, \boldsymbol{T}} \circ \boldsymbol{U}\right) \boldsymbol{J}_{N_{T}, 1} \\
\boldsymbol{T}^{\mathrm{T}}=\boldsymbol{J}_{1, N_{D}}\left(\boldsymbol{M}_{\boldsymbol{D}, \boldsymbol{T}} \circ \boldsymbol{U}\right)
\end{gathered}
$$

Mappings $\boldsymbol{M}_{\boldsymbol{H}, \boldsymbol{P}}, \boldsymbol{M}_{\boldsymbol{P}, \boldsymbol{G}}, \boldsymbol{M}_{\boldsymbol{G}, \boldsymbol{C}}$ and $\boldsymbol{M}_{\boldsymbol{G}, \boldsymbol{N}}$ define exclusive relationships, as heat generators can only be located in one premises, premises can only be connected to one GCP etc. Below equation (3) shows the relationship between premises import/export $(\boldsymbol{P})$ and GCP import/export $(\boldsymbol{G})$, for each scenario and time step. Similar relationships can be defined using each of the exclusive mappings shown in Figure 2.

$$
\boldsymbol{P}=\boldsymbol{M}_{P, G} \boldsymbol{G}
$$

The key benefits of the mapping approach adopted are its flexibility and scalability, particularly to simplified local network modelling. However, it should be noted that for full consideration of losses and capacity, voltage, pressure and flow constraints, at cost of substantial extra complexity, network modelling should also be incorporated $[35,36]$.

Based on the mappings an optimisation model for the DMES under study can be built. As mentioned earlier, in the context of price-driven transactive energy demand response, any optimisation model that responds to multi-service price signals could be adopted. For the case study described in Section 3 a two-stage, day-ahead stochastic optimisation model, which is capable of considering multiple services, including energy arbitrage and reserve/capacity services, and multiple sources of flexibility is used, and described briefly in Section 2.1.1. 


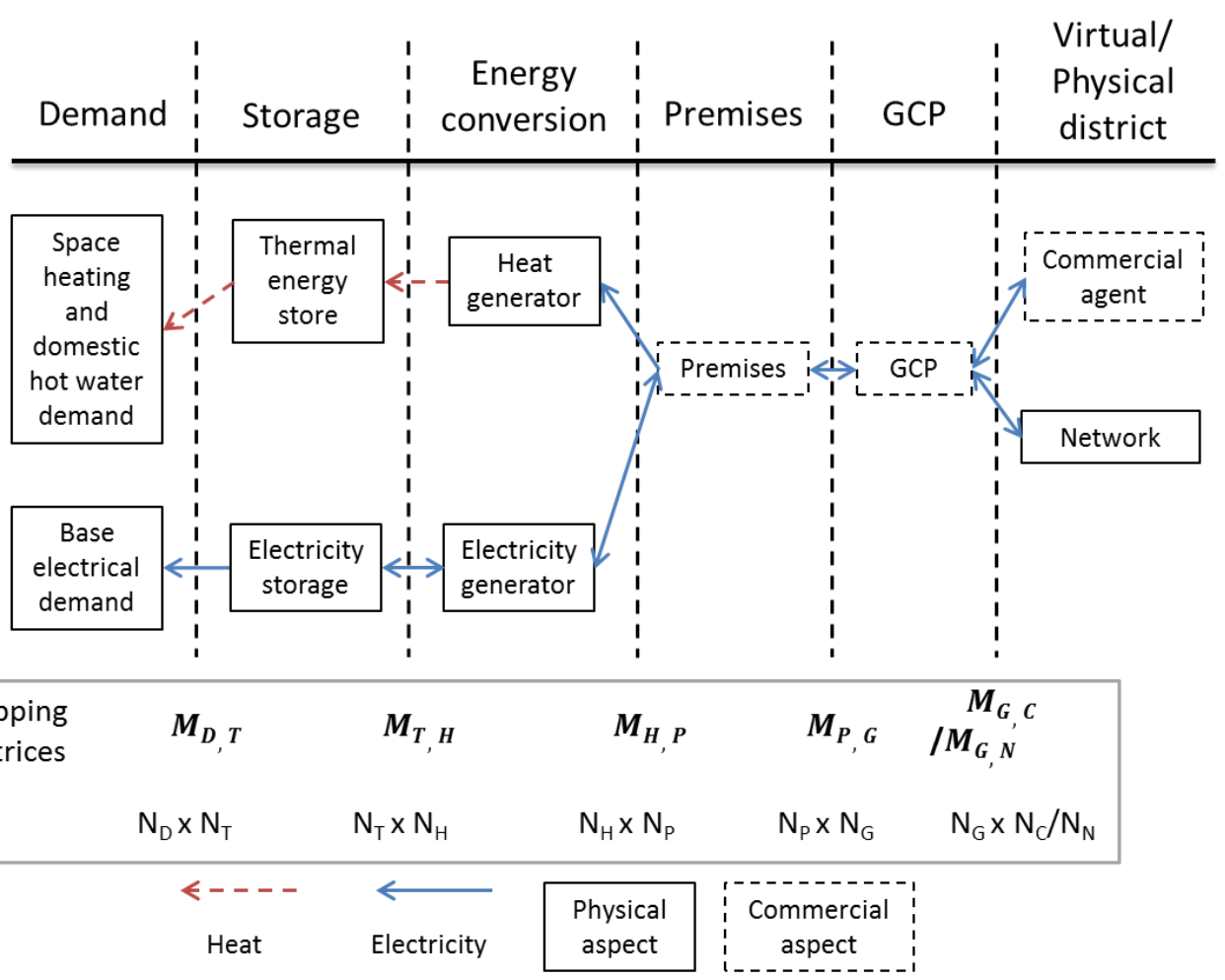

\subsubsection{Optimisation model formulation}

A key feature of the formulation is the use of an objective function that differentiates between district, GCP and premises level energy balances, which facilitates the modelling of virtual and physical aggregation [33] see (4). As mentioned, the optimisation is a stochastic one with $N_{s}$ number of scenarios, each with probability of occurrence $p_{s}$, conducted over $N_{i}$ periods. It is a two-stage problem with the first stage decision being the import and export on the day-ahead market $\left(D_{i, c}^{-}\right.$and $D_{i, c}^{+}$respectively) and the capacity market commitment $\left(C_{s, c}\right)$. All other decision variables are set in the second stage, including import/export on the imbalance market $\left(I_{s, i, c}^{-} / I_{s, i, c}^{+}\right)$and the electricity import/export and the GCP and premises level $\left(E(g)_{s, i, g}^{-}, E(g)_{s, i, g}^{+}\right.$, $\left.E(p)_{s, i, p}^{-}, E(p)_{s, i, p}^{+}\right)$. Regarding the capacity commitment $\left(C_{s, c}\right)$, this attracts revenue according to the availability price $\left(\pi_{s, i}\right)$ during the relevant capacity windows (indicated by $C_{i}^{\text {window }}$ ), and according to the call price $\left(\omega_{s, i}\right)$ during the capacity calls (indicated by $\left.C_{s, i}^{\text {call }}\right)$. More detail on capacity/reserve modelling can be found in [37].

Consistent with Figure 2 and [33] there can be multiple commercial agents $\left(N_{c}\right), \operatorname{GCPs}\left(N_{g}\right)$ and premises $\left(N_{p}\right)$, with the relationships between commercial agents, GCPs and premises dictated by the mappings $\boldsymbol{M}_{\boldsymbol{P}, \boldsymbol{G}}$ and $\boldsymbol{M}_{G, C}$ (see section 2.1).

$$
\begin{aligned}
\operatorname{Min}\left\{\sum _ { s = 1 } ^ { N _ { s } } \sum _ { i = 1 } ^ { N _ { i } } \left[p_{s}\right.\right. & \left(\sum_{c=1}^{N_{c}} \lambda_{i}^{-} D_{i, c}^{-}-\lambda_{i}^{+} D_{i, c}^{+}+\mu_{s, i}^{-} I_{s, i, c}^{-}-\mu_{s, i}^{+} I_{s, i, c}^{+}-\left(C_{i}^{\text {window }} \pi_{s, i}+C_{s, i}^{c a l l} \omega_{s, i}\right) C_{s, c} t\right) \\
& +\sum_{g=1}^{N_{g}}\left(\chi(g)_{i, g}^{-} E(g)_{s, i, g}^{-}+\chi(g)_{i, g}^{+} E(g)_{s, i, g}^{+}\right) \\
& \left.\left.\left.+\sum_{p=1}^{N_{p}}\left(\chi(p)_{i, p}^{-} E(p)_{s, i, p}^{-}+\chi(p)_{i, p}^{+} E(p)_{s, i, p}^{+}\right)\right)\right]\right\}
\end{aligned}
$$


storage resources. Although the full model is not presented here for brevity, a key constraint to be mentioned is the network constraint. As shown in (5), and in line with Figure 2, the electricity balance at the GCP level must be mapped to the physical network level using $\boldsymbol{M}_{\boldsymbol{G}, \boldsymbol{N}}$ to ensure that import/export on each network is below the network limit $\left(\gamma_{n}\right)$.

$$
\boldsymbol{M}_{\boldsymbol{G}, \boldsymbol{N}} \frac{\left(E(g)_{s, i, g}^{-}-E(g)_{s, i, g}^{+}\right)}{t} \leq \gamma_{n}
$$

For further details on the model the reader is directed to [37].

\subsection{Value mapping}

Building on the BusMod methodology [38], this paper introduces a method which is similarly based on exchanges of cash/commodities/services, but may be considered more suitable for strategic, practical and clear assessment of operational cash flows in a transactive energy framework. The value mapping method is required to a) identify the price signals and hence cash flows relevant to the system studies, and b) identify and quantify the effects of any business case on the wider energy system and actors. Compared to the simpler price mapping approach presented in [33] a key contribution of the developed mapping methodology is the distinction between roles and actors. This distinction allows appreciation of the complexity of different roles that may be fulfilled by a number of actors, which is a necessary feature to distinguish impacts on the various roles of an actor separately. The second key difference of the presented approach compared to the approach in [33] is its modularity and extensibility. By basing the approach on exchanges, rather than focusing on the final energy consumer as in [33], the approach becomes more general. This makes it suitable for use to investigate network effects associated with specific actions by given actors, as well as for extension to consider upstream and downstream effects and also for consideration of other sectors (e.g., transport) which interact with the energy system.

In the graphical representation described below, roles are distinguished by black-bordered boxes, whilst actors are represented by coloured un-bordered boxes (see Figure 3). Actors are classified according to their primary sector (e.g., electricity, gas, heat or government), with classification denoted by colour. Exchanges of commodities/services and cash between roles are represented by arrows, as shown in Figure 3. Flows can be classified according to type, with classification denoted by arrow colour. Various flows of commodities/services are possible, especially if the mapping is extended into heating and transport sectors. Figure 3 demonstrates mapping between actors that can be expected to be common in assessment of for example, districts.

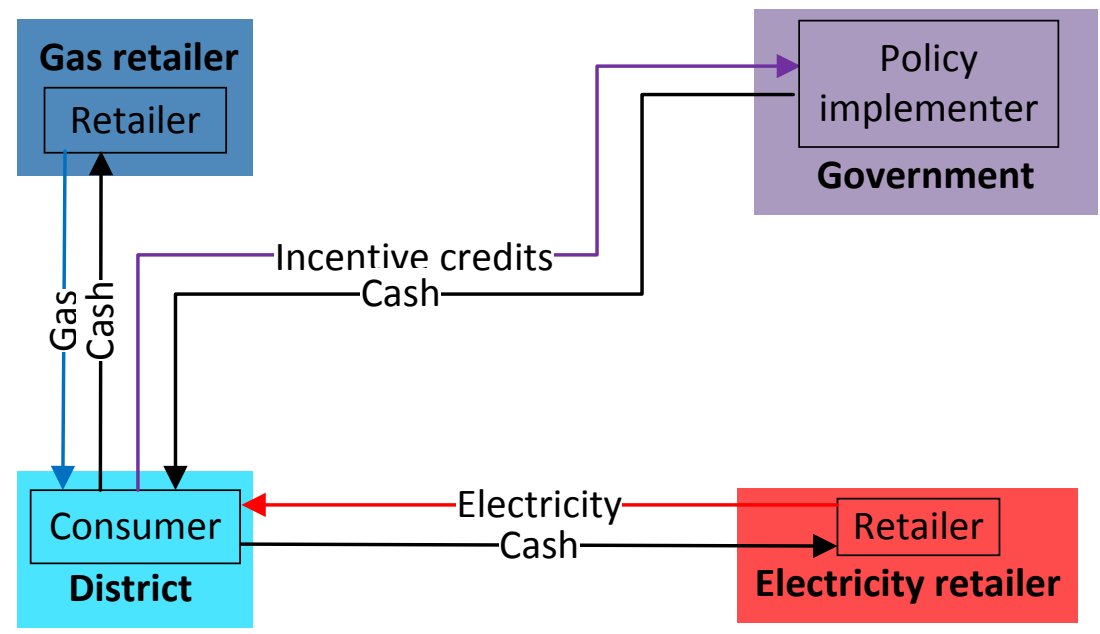

Figure 3: Example of flows between roles/actors 
Focusing on a district, once the whole energy system has been described graphically, the topology can be used to define matrices for mapping district cash flows (which result from the DMES model, see Section 2.1), to roles, and then roles to actors. This mapping can then be used to quantify the direct and indirect effect of district optimisation on all energy system actors. Equation (6) shows how the district to role map $\left(\boldsymbol{M}_{\boldsymbol{C}, \boldsymbol{R}}\right)$, a matrix with each entry either 0 (no mapping), 1 (positive cash flow) or -1 (negative cash flow) relates district cash flows $(\boldsymbol{C})$ to role cash flows $(\boldsymbol{R})$. Similarly equation (7) shows how the role to actor map $\left(\boldsymbol{M}_{\boldsymbol{R}, \boldsymbol{A}}\right)$, a binary matrix, relates role cash flow to actor cash flow $(\boldsymbol{A})$.

$$
\begin{aligned}
& C=M_{C, R} R \\
& R=M_{R, A} A
\end{aligned}
$$

\subsection{Profit sharing model}

The above defined value mapping method is suitable for defining exchanges between actors who are engaging in a purely transactive fashion, without consideration of profit sharing. However, it is likely that consumers within a district may choose more service-orientated relationships with a retailer and/or aggregator actor(s) (whilst relationships between retailers/aggregators and other energy system actors remain transactive). The framework discussed here therefore also incorporates two examples of options for profit sharing which would address these two extremes (transactive and service-based), namely, consumer led and retailer-aggregator led.

The retailer-aggregator led option is based on the standard current relationship between consumers and retailers, with retailers charging consumers for electricity according to a flat retail tariff. The flat tariff ( $€ / \mathrm{kWh})$, for a particular case is calculated as in (8), where $E \cos t_{\text {base }}^{R A D}$ is the retailer-aggregator-district (RAD) annual cost of electricity in the base case (i.e., the cost of energy at the boundary of these roles), $B C R_{\text {case }}^{D}$ is the district's share of the additional revenue from following the considered business case, $P M$ is the required retailer annual profit margin and Elec $_{\text {case }}$ is the electricity consumption for the given case.

$$
\text { Tariff }=\frac{E \cos t_{\text {base }}^{\text {RAD }}-B C R_{\text {case }}^{D}+P M}{\text { Elec }_{\text {case }}}
$$

A central assumption in this method is that the retailer-aggregator requires that its profit margin from energy retailing does not decline as a result of any business case. To ensure this, the retail tariff changes in response to changes in demand, varying upwards or downwards to ensure that the retailer continues to collect their pre-defined retail-related profit margin. In addition to variation motivated by changes in overall demand, the retail tariff will also vary in order to allocate the consumer its (contractually agreed) share of the business case benefits. In this way the retailer-aggregator precludes disruption to their main business (energy retail), whilst both the retailer-aggregator and consumer access the benefits associated with new, flexibility-related business cases. For the retailer-aggregator led case, the district revenue $\left(\operatorname{Re} v_{\text {case }}^{D}\right)$ is a function of the calculated tariff (see (8)) and the electricity consumption (9). The retailer-aggregator revenue is a function of the retaileraggregator's share of the revenue from following the considered business case $\left(B C R_{\text {case }}^{R A}\right)$, the district revenue and base RAD overall energy costs (10). The net flow of profit within the district for the retailer-led case is demonstrated in Figure 4 (a).

$$
\begin{gathered}
\operatorname{Rev}_{\text {case }}^{D}=- \text { Tariff } * \text { Elec }_{\text {case }} \\
\text { Rev }_{\text {case }}^{\text {RA }}=B C R_{\text {case }}^{\text {RA }}+\operatorname{Rev}_{\text {case }}^{D}-E_{\text {cost }}^{\text {Rad }} \text { base }
\end{gathered}
$$

The consumer led option is a more radical approach, where the consumer(s) retain(s) control over the district flexible plant and faces market prices, directly transposed by the retailer-aggregator from various markets. In this option, all profit from flexibility exploitation accrues to the consumer. The consumer then remunerates the retailer-aggregator for its role as an energy retailer and for transposing energy-related prices and, if applicable, prices related to provision of any energy system services (e.g., balancing services). District revenue 
is as calculated in (11), where $R e v_{\text {case }}^{D}$ is the annual revenue from the considered business case and $S F$ is the service fee payable to the retailer-aggregator. As shown in (12), the retailer-aggregator revenue is equal to the service fee. The net flow of profit within the district for the consumer-led case is demonstrated in Figure 4 (b).

$$
\begin{gathered}
\operatorname{Rev}_{\text {case }}^{D}=B C R_{\text {case }}^{D}-S F \\
\operatorname{Rev} v_{\text {case }}^{R A}=S F
\end{gathered}
$$

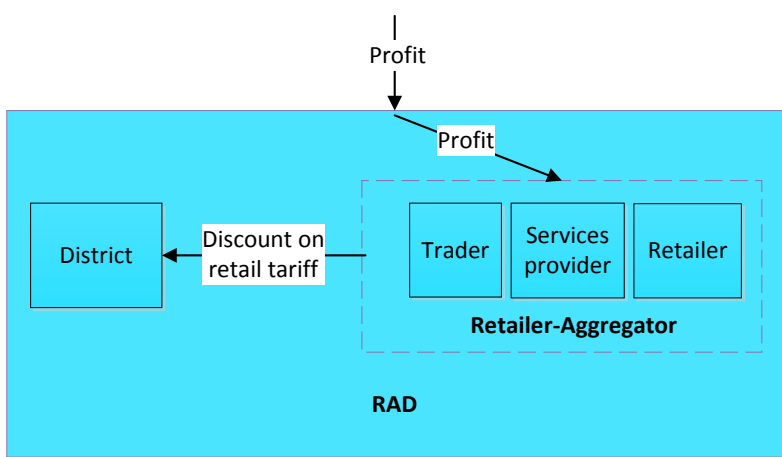

a)

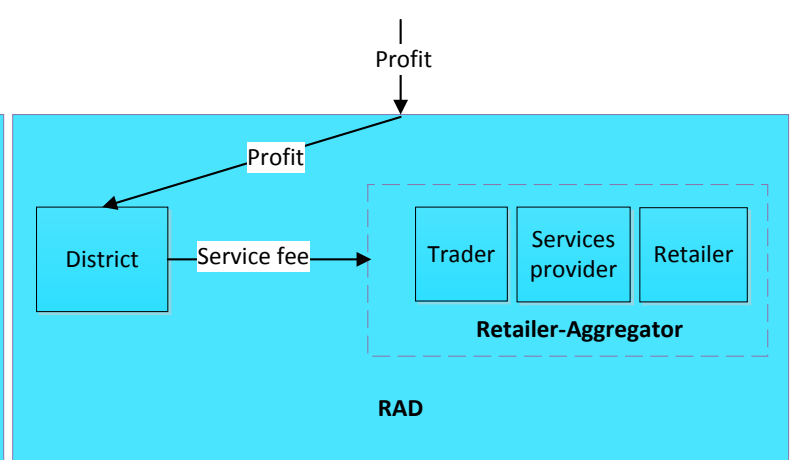

b)
4

Figure 4: District profit flow, retailer-led case (a), and consumer-led case (b)

\subsection{Economic assessment}

The economic assessment models comprise a portfolio of common CBA metrics preferred by different actors for assessment of business cases. For instance, typically driven by the regulatory framework in place, network operators tend to prefer investment assessment metrics, particularly the net present value (NPV) criterion (measure of discounted benefits and discounted costs over the project lifetime), payback time (the period that is required for the project to become profitable), and internal rate of return (IRR; the exact premium that a business case is offering in exchange for all costs incurred, or, more precisely, the discount rate that renders the present value of both benefits and costs the same).

\section{Case study description}

In this section, the use of the proposed modelling and assessment framework is exemplified below in the analysis of six business cases undertaken for a French district of commercial buildings.

\subsection{The district}

The district on which the business case studies are undertaken is made up of six office buildings. Annual (nonheat-related) electricity demand for the district is 4,800 MWh, whilst annual heat demand is $11,400 \mathrm{MWh}$. Electricity and heat half-hourly profiles for the district for a typical day for each season are given in Figure 5 and Figure 6. Summer weekday/weekend, shoulder (spring/autumn) weekday/weekend, winter weekday/weekend and "peak" seasons are considered ${ }^{2}$. As shown, peak electricity demand is $910 \mathrm{~kW}$, whilst peak heat demand is $2,150 \mathrm{~kW}$.

The district is under common ownership and connected to the public electricity distribution network through a single connection. Thus, it can be considered both physically and commercially aggregated [33]. Further, the district is connected by a heat network. Heat is produced in a central heat facility by a modern and efficient $170 \mathrm{~kW}$ electric heat pump (EHP; coefficient-of-performance around 4, depending on the specific conditions), and a $1650 \mathrm{~kW}$ electric boiler (assumed as $100 \%$ efficient). Further, the district includes $4400 \mathrm{~kW}$ diesel-fired

\footnotetext{
${ }^{2}$ There is distinction in the demand data between winter weekday and "peak", as this distinction is relevant to market factors rather than demand factors, see Section 3.3.
} 
1 electricity generation (32\% efficient), thermal storage (250,000 litres hot water storage) and battery storage

2 (660kWh capacity, $180 \mathrm{~kW}$ charge rate, $720 \mathrm{~kW}$ discharge rate, $90 \%$ round-trip efficiency). The parameters are summarised in Table I.

4

\begin{tabular}{|l|l|l|l|l|}
\hline Energy converter & Max Power & Efficiency/COP & Capacity \\
\hline EHP & $170 \mathrm{~kW}$ & COP=4 & \\
\hline Electric boiler & $1650 \mathrm{~kW}$ & $100 \%$ & \\
\hline Diesel generator & $4400 \mathrm{~kW}$ & $32 \%$ & \\
\hline Thermal storage & & & $\begin{array}{l}250000 \text { litres } \\
\left(40^{\circ} \mathrm{C}-55^{\circ} \mathrm{C} \text { range }\right)\end{array}$ \\
\hline Battery storage & & $\begin{array}{l}180 \mathrm{~kW} \text { (charging) } \\
720 \mathrm{~kW} \text { (discharging) }\end{array}$ & $90 \%$ & $660 \mathrm{kWh}$ \\
\hline
\end{tabular}

Figure 5: District electricity profiles, by season

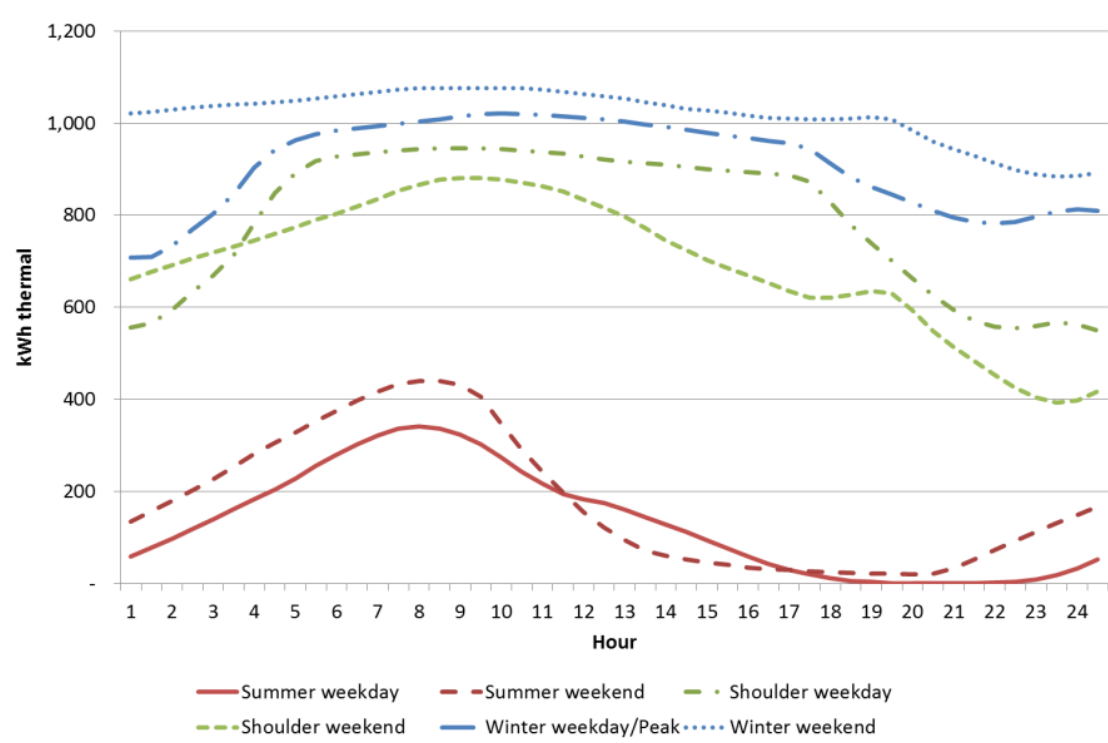

Figure 6: District heat profiles, by season

Table I: Case study energy conversion and storage parameters

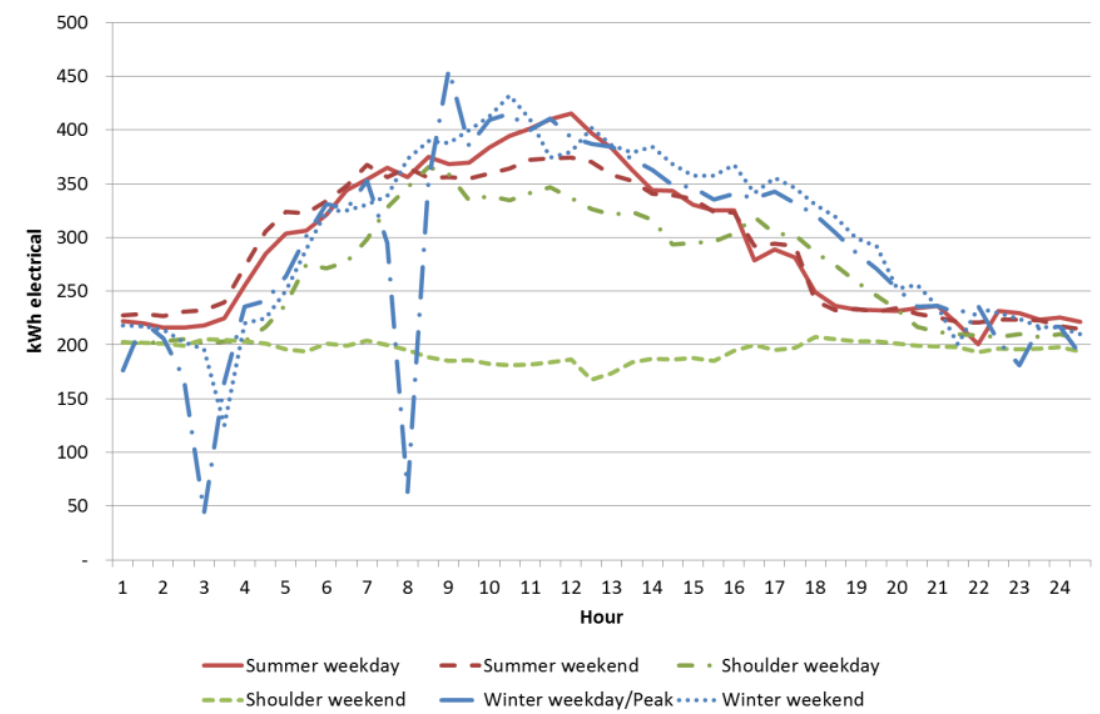




\subsection{Energy system and price signals}

Roles and actors for the French energy system, and the price signals which quantify the exchanges between them, are defined as in Figure 7. In this mapping the retailer, aggregator and district (consumer) roles are fulfilled by the RAD actor. This arrangement enables various retailer-aggregator-district arrangements to be considered, two of which are demonstrated in Section 4.3. Also shown in Figure 7 are ellipses showing the relation of different exchanges to the price signal based business cases ${ }^{3}$. More details are given in Section 3.3.

Wholesale electricity prices are taken from the EPEX Spot platform, which operates day-ahead and intraday markets [39]. Wholesale electricity prices are relevant for business case 1, optimised purchase on the wholesale market (OPWM; see Section 3.3).The RAD will also receive or make payments from/to the electricity transmission system operator (ETSO) if the district is imbalanced [39]. Imbalance prices (together with wholesale prices) are relevant for business case 2, minimisation of imbalance penalties (MIP; see Section 3.3). The RAD may also receive payments from the ETSO for capacity provision, in the capacity market (which will operate in France from year 2016/17). To participate in this market capacity owners must be available during peak hours, which are expected to occur on 10-25 days between 07:00h-15:00h and 18:00h-20:00h [40]. The capacity market is relevant for business case 3, capacity market (CM; see Section 3.3). A distribution use-ofservice (DUOS) fee is paid to the electricity distribution network operator (EDNO), to pay for network operation and maintenance. As detailed in [41], several tariffs are available. As only the subscription charge $(€ / \mathrm{kW})$ can change through the pursuance of any business case, only this element, as detailed in [41], is considered in this work. The DUoS fee is relevant for the UoS fee business case (business case 5; see Section 3.3).

Further price signals, which are considered in business case 6, are the balancing responsible entity (BRE) fee, value-added-tax (VAT) and environmental and social obligations (ESO). BRE fees are required by the system operator to pay for procurement of balancing services, to maintain the security of the grid.

\subsubsection{Price profiles}

Figure 8 shows price profiles, across the 48 settlement periods of the day, disaggregated by price component for the seven representative days considered in this work. Note that there is no UoS component in the graphs of Figure 8 as, for the tariff being considered (see Section 3.2), UoS fees are charged based on the subscribed power of the user. The capacity market availability price shown in Figure 8 is set based on a capacity price of $€ 30 / \mathrm{kW}$, and assumes that a capacity call is equally likely over the 15 days of the modelled peak period, and the 10 hours per day in which capacity may be called. The solid lines represent the total district import/export prices at the day-ahead (wholesale) stage, whilst the dotted lines represent total district import/export prices for real-time transactions.

As mentioned earlier, business cases are measured against a baseline case, in which optimisation is conducted on retail prices (although the district remunerates relevant parties according to market rates). For these cases retail prices are set based on a typical tariff for large commercial users, see Table II.

\footnotetext{
${ }^{3}$ Business cases 4 and 6 are not shown in Figure 7 as business case 4 is based on relaxing the security constraints of the optimisation, rather than a price signal, and business case 6 is the combination of all business cases.
} 


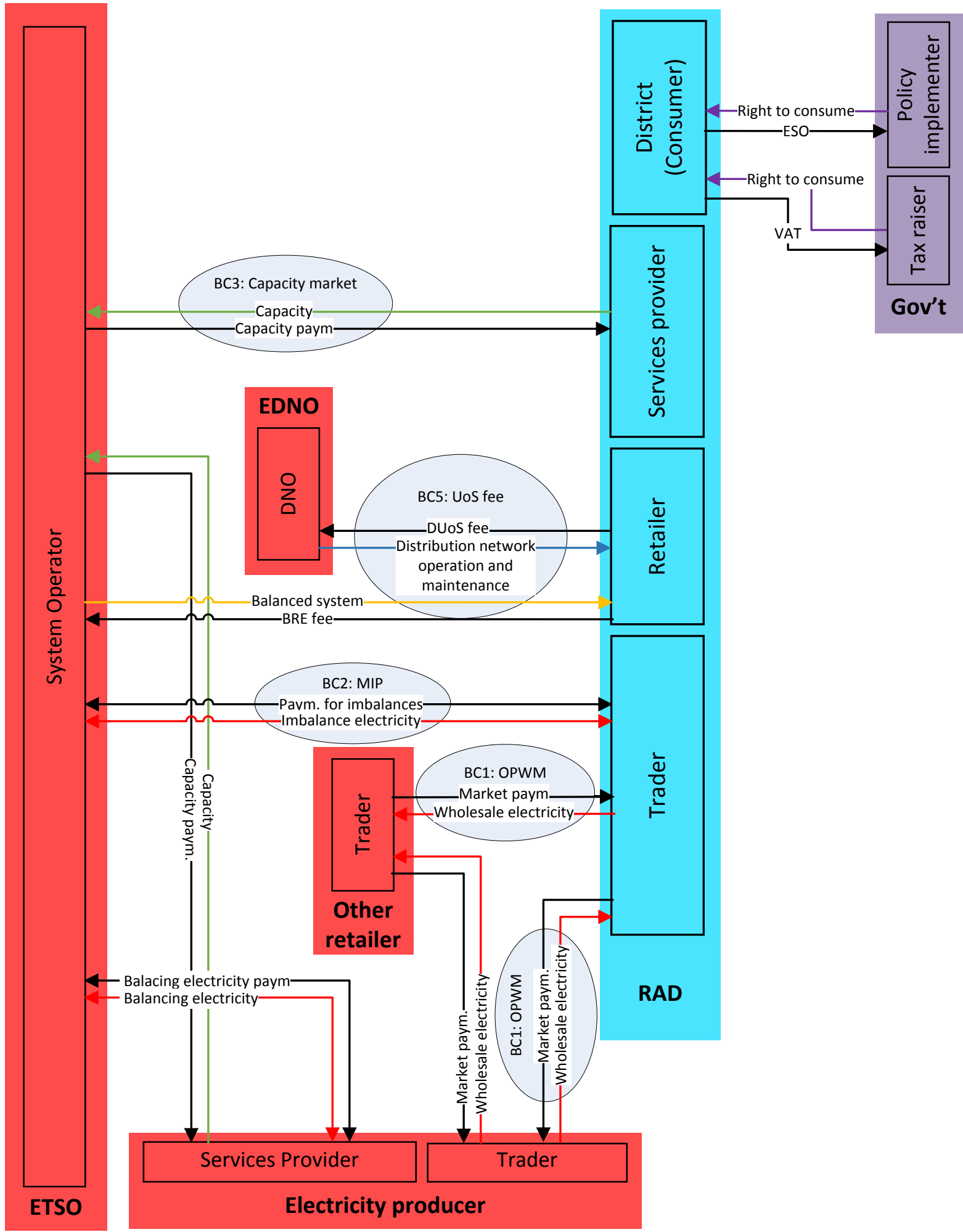

$$
\text { Key }
$$

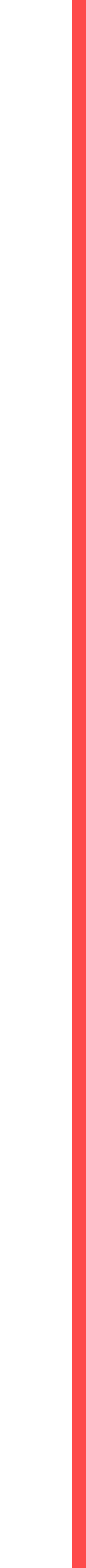

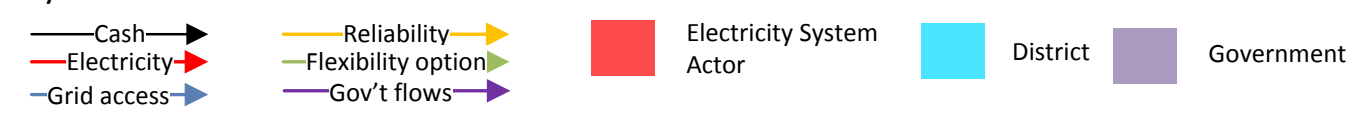



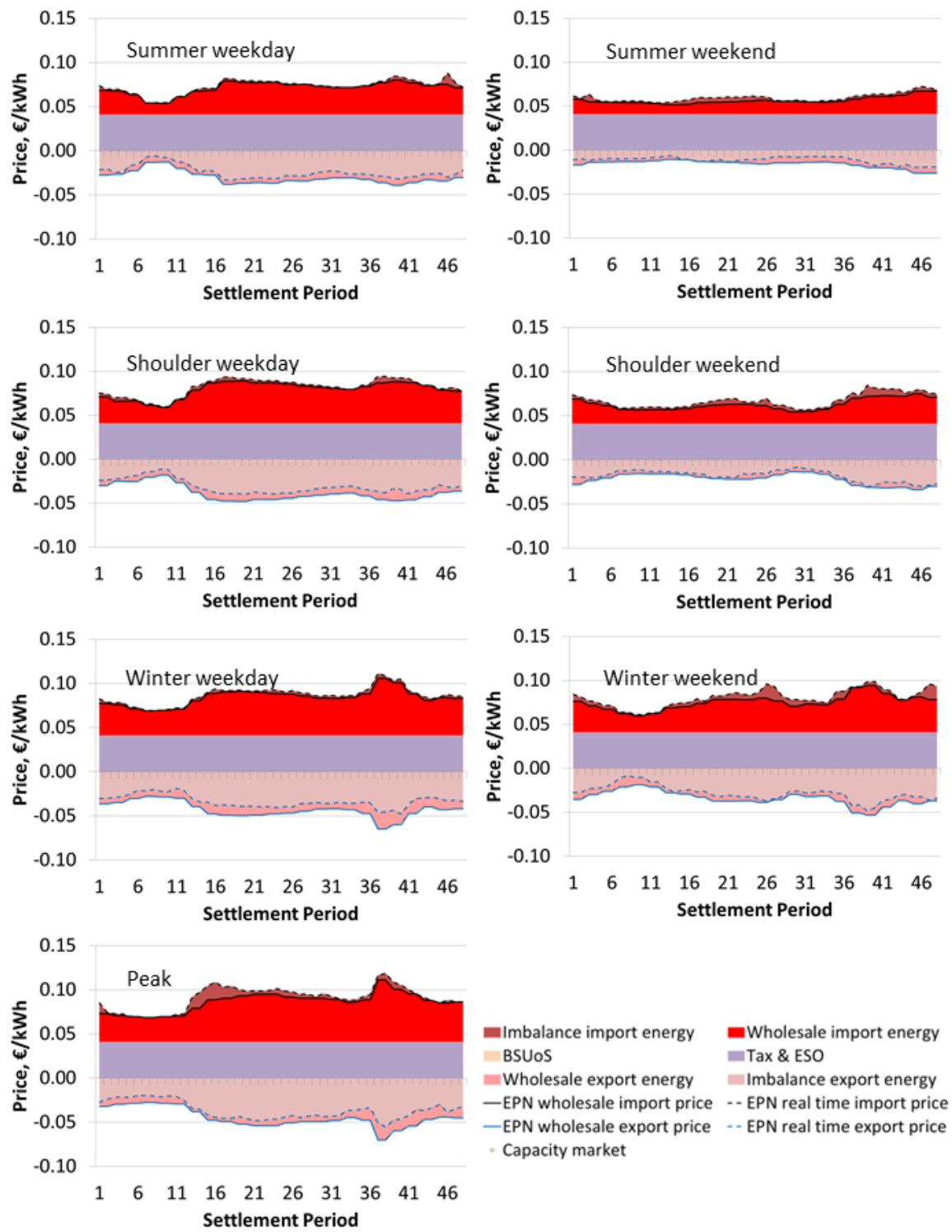

Figure 8: French district electricity prices, by season, by component

Table II: Retail tariffs

\begin{tabular}{|l|l|l|l|l|}
\hline \multirow{2}{*}{} & \multicolumn{2}{|c|}{ November-March } & \multicolumn{2}{c|}{ April-October } \\
\cline { 2 - 5 } & \multicolumn{2}{|c|}{ Monday-Saturday } & \multicolumn{2}{c|}{ Monday-Saturday } \\
\cline { 2 - 5 } & $0600-2200$ & $2200-0600$ & $0600-2200$ & $2200-0600$ \\
\hline Import & $15.14 \mathrm{c} / \mathrm{kWh}$ & $12.95 \mathrm{c} / \mathrm{kWh}$ & $13.71 \mathrm{c} / \mathrm{kWh}$ & $11.52 \mathrm{c} / \mathrm{kWh}$ \\
\hline Export & $6.79 \mathrm{c} / \mathrm{kWh}$ & $4.60 \mathrm{c} / \mathrm{kWh}$ & $5.36 \mathrm{c} / \mathrm{kWh}$ & $3.16 \mathrm{c} / \mathrm{kWh}$ \\
\hline & \multicolumn{3}{|c|}{ Sunday } & \multicolumn{2}{c|}{ Sunday } \\
\hline Import & \multicolumn{2}{|c|}{$12.95 \mathrm{c} / \mathrm{kWh}$} & \multicolumn{2}{c|}{$11.52 \mathrm{c} / \mathrm{kWh}$} \\
\hline Export & \multicolumn{2}{|c|}{$4.60 \mathrm{c} / \mathrm{kWh}$} & \multicolumn{2}{c|}{$3.16 \mathrm{c} / \mathrm{kWh}$} \\
\hline
\end{tabular}

\section{$4 \quad 3.3 \quad$ Business cases}

5 In this study, six business cases (in addition to a baseline case, business case 0 ) are considered. These business

6 cases are pursued by the lead actor within the RAD (see Section 2.3), by controlling and optimizing the district

7 flexible plant (i.e., EHP, electric boiler, diesel electricity generator and associated thermal/electrical storage; 
see Section 3.1), in response to the relevant price signals (see Section 3.4). The business case are described below, and summarised in Table III (including explanation of the acronyms used).

- Business case 0: All business cases described below are measured against this 'baseline' case, in which the district optimises with respect to regular retail prices. Likely behaviour in this case, in response to the retail prices detailed in Table II, will be to shift district electricity consumption away from higher price import periods, using the thermal and electrical storage. As the retail prices do not directly reflect wholesale electricity prices, and other price components, the benefit of this optimisation will be limited.

- Business case 1: The first business case, namely, OPWM, is an energy-oriented business case. Here, the lead actor is exposed to electricity day-ahead wholesale market prices (see Section 3.2), and attempts to minimise expenditure by utilising district flexibility to shift grid electricity consumption away from high price periods to low price periods, at the day-ahead stage.

- Business case 2: The MIP business case is a flexibility-oriented one. For this case, the lead actor perceives, in addition to electricity day-ahead wholesale market prices, penalties associated with imbalance, i.e., the difference between actual consumption and purchase in the wholesale market (which can differ as wholesale market purchases are conducted at the day-ahead stage, and final energy demand is uncertain).

- Business case 3: In the CM business case, which is a capacity-oriented one, the district perceives the capacity price and seeks to maximise their potential electricity consumption reduction by shifting consumption to periods of network stress (which may count as capacity). These are assumed to occur, with equal likelihood on a "peak" day.

- Business case 4: The fourth considered business case is based on the 'Distribution Network Constraint Management' (DNCM) service. In this case optimisation is conducted on retail price signals and it is assumed that the normal $\mathrm{N}-1$ security standards can be violated, due to the availability of DR in the district [42]. This allows the district to import/export electricity in excess of the nominal sub-station transformer rating, if it is profitable, according to the retail price signals.

- Business case 5: In this UoS fee business case the lead actor seeks to minimise UoS fee payments. In France, as described in Section 3.2, UoS fees are charged according to subscribed power, and hence optimisation is conducted by minimising the maximum power demand of the district. The derivation of UoS fees from the capacity of the connection makes this business akin to a capacity-oriented case.

- $\quad$ Business case 6: Finally, an optimisation with respect to all price signals is also considered.

Table III: Business case descriptions

\begin{tabular}{|c|l|l|l|}
\hline Business case \# & Business case name & Acronym & Description \\
\hline 0 & Baseline & Optimisation with respect to the regular retail prices \\
\hline 1 & $\begin{array}{l}\text { Optimised purchase on } \\
\text { wholesale market }\end{array}$ & OPWM & $\begin{array}{l}\text { Optimisation of participation in wholesale electricity } \\
\text { markets }\end{array}$ \\
\hline 2 & $\begin{array}{l}\text { Minimisation of } \\
\text { imbalance penalties }\end{array}$ & MIP & $\begin{array}{l}\text { Minimisation of imbalance penalties, in addition to } \\
\text { optimisation of wholesale market participation }\end{array}$ \\
\hline 3 & Capacity market & CM & Maximisation of capacity market revenue \\
\hline 4 & $\begin{array}{l}\text { Distribution network } \\
\text { constraint } \\
\text { management }\end{array}$ & DNCM & $\begin{array}{l}\text { Optimisation given the ability (due to district DR } \\
\text { capability) to violate local network capacity } \\
\text { constraints }\end{array}$ \\
\hline 5 & Use of system fees & UoS & Minimisation of payment of UoS fees \\
\hline 6 & All price signals & All & Optimisation on all relevant price signals \\
\hline
\end{tabular}

\subsection{Optimisation engine and assessment of the operational cash flows}

The decision variables in the district optimisation model are the electricity/thermal generation/storage plant set-points, grid electricity import/export, and, in appropriate cases, capacity provision. The main optimisation seeks to minimise district energy costs/maximise revenues from services, in line with [16], with price 
components applied at the premises, GCP and commercial level as in [33]. The district is both (thermally and electrically) physically and commercially aggregated. Focusing on the heating network and electrical premisescommercial agent/network mappings, aggregation matrices are set as defined in Table IV. As the district is under one owner, connected to the wider electricity network via one GCP, optimised as one and situated on a single electricity network, $\boldsymbol{M}_{\boldsymbol{P}, \boldsymbol{G}}, \boldsymbol{M}_{\boldsymbol{G}, \boldsymbol{C}}$ and $\boldsymbol{M}_{\boldsymbol{G}, \boldsymbol{N}}$ are all 1x1 matrices. Figure 9 shows these mappings graphically.

Table IV: District matrix mappings

\begin{tabular}{|c|c|l|}
\hline Matrix & Structure & \multicolumn{1}{c|}{ Description } \\
\hline$M_{\boldsymbol{D}, \boldsymbol{T}}$ & {$\left[\begin{array}{l}1 \\
1 \\
1 \\
1 \\
1 \\
1\end{array}\right]$} & $\begin{array}{l}\text { Maps demand from the six district buildings to } \\
\text { one TES }\end{array}$ \\
\hline $\boldsymbol{M}_{\boldsymbol{T}, \boldsymbol{H}}$ & {$\left[\begin{array}{ll}1 & 1\end{array}\right]$} & $\begin{array}{l}\text { Maps the one TES to the two heat generators } \\
\text { (one EHP and one electric boiler) }\end{array}$ \\
\hline $\boldsymbol{M}_{\boldsymbol{H}, \boldsymbol{P}}$ & {$\left[\begin{array}{l}1 \\
1\end{array}\right]$} & Maps the two heat generators to one premises \\
\hline $\boldsymbol{M}_{\boldsymbol{P}, \boldsymbol{G}}$ & {$[1]$} & Maps the single premises to a single GCP \\
\hline $\boldsymbol{M}_{\boldsymbol{G}, \boldsymbol{C}}$ & {$[1]$} & $\begin{array}{l}\text { Maps the single GCP to a single commercial } \\
\text { agents }\end{array}$ \\
\hline $\boldsymbol{M}_{\boldsymbol{G}, \boldsymbol{N}}$ & {$[1]$} & $\begin{array}{l}\text { Maps the single GCP to a single electricity } \\
\text { network }\end{array}$ \\
\hline
\end{tabular}

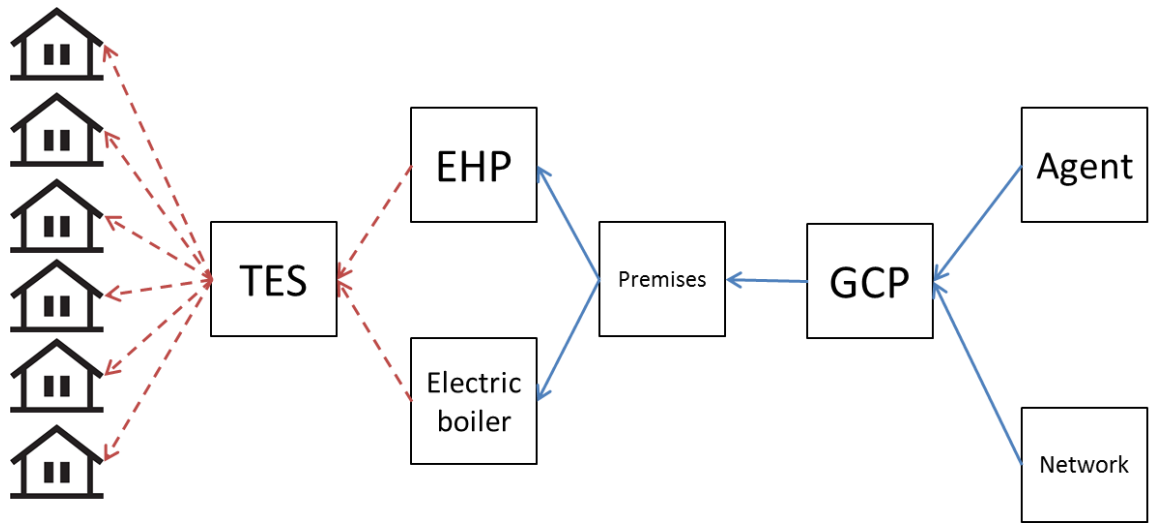

Figure 9: Graphical representation of district mappings

Each business case is evaluated for seven typical days corresponding to specific seasons and period of the week, namely summer weekday/weekend, shoulder (spring/autumn) weekday/weekend, winter weekday/weekend and "peak" season. The numbers of days represented by the various model days, which are used to calculate annual results, are as shown in Table V.

Table V: Season definition

\begin{tabular}{|c|c|}
\hline Season & $\begin{array}{c}\text { Number } \\
\text { of days }\end{array}$ \\
\hline Summer weekday & 66 \\
\hline Summer weekend & 26 \\
\hline Shoulder weekday & 131 \\
\hline Shoulder weekend & 52 \\
\hline Winter weekday & 49 \\
\hline Winter weekend & 26 \\
\hline Peak & 15 \\
\hline
\end{tabular}


The optimisation model was implemented using the FICO Xpress Optimizer [43] on a computer with a $3.6 \mathrm{GHz}$ processor and 32 GB RAM. Each modelled day ran in 7 minutes on average.

\section{Results and discussion}

Below, in Section 4.1, the RAD cash flows from the various business cases are presented and discussed. Subsequently, in Section 4.2, the effect of district optimisation on the various other actors of the energy system is studied in an example for the 'All' business case (optimisation on all price signals). Then in Section 4.3 , the retail tariffs and consumer cash flow resulting from the profit sharing model are presented. Finally in Section 4.4 the NPV of the various business cases are presented and discussed.

\subsection{Business case cash flows}

Figure 10 shows the change in cash flows associated with the various price components and the considered business cases for the district, compared to the baseline retail optimisation case (see Section 3.3). As shown, the OPWM and MIP business cases produce net increases in operational revenue, compared to the baseline case, of $€ 14,000 /$ year and $€ 20,000 /$ year, respectively. In both cases there is increased revenue as expenditure on imbalance electricity is reduced, which is tempered by an increase in expenditure on wholesale electricity. The CM business case produces a much larger increase, of $€ 202,000 /$ year, which is almost entirely due to revenue obtained from the capacity market. The change in revenue for the DNCM case is negligible, whilst the UoS case produces an increase of $€ 43,000 /$ year, with most revenue from reduction in UoS fee costs.

Consideration of all price signals produces an increase in operational revenue of $€ 247,000$ /year, with changes in each component largely reflecting the revenue changes in the individual cases, though slightly tempered as different price signals sometimes produce conflicting incentives.

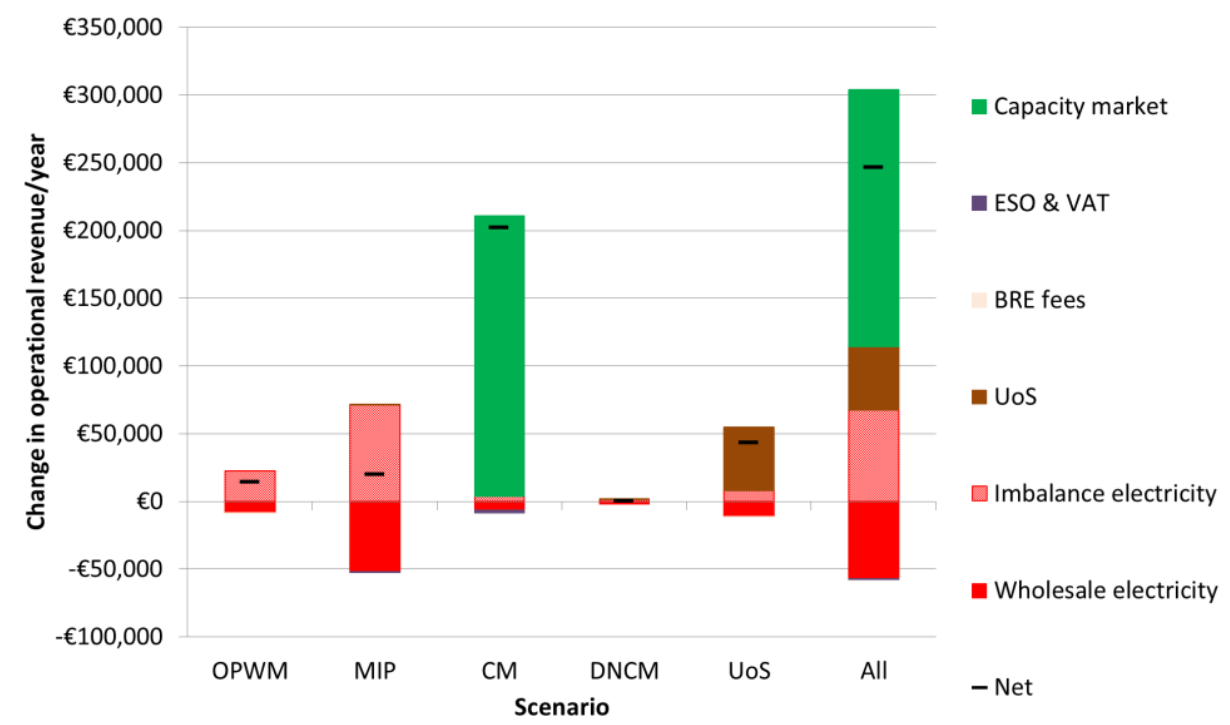

Figure 10: Change in RAD operational cash flows - various business cases compared to the baseline case

For the demonstrated results, a key point of note is that whilst optimisation is with respect to particular price signals for each case, there can be substantial impacts on the cash flows related to other price components. This observation demonstrates the importance and power of the price disaggregation and mapping methodology, which enables this type of emergent system behaviour to be captured. A clear example of this effect can be seen in the OPWM business case, in which the district wholesale electricity cash flow actually decreases, compared to the baseline case, as total cash flow increases. This occurs because, after the business case optimisation, which shifts electricity demand away from high wholesale market price periods, the secondary market optimisation shifts electricity purchase away from imbalance market to the wholesale 
market. As demand is less uncertain in cheaper periods ${ }^{4}$, there is more scope for the secondary optimisation to increase revenue by shifting to the purchase wholesale market. This clearly demonstrates the importance of the value mapping method (as well as a sophisticated district optimisation model) to enable capture of these effects.

For the MIP business case, change in revenue compared to the baseline case is slightly larger compared to the OPWM business case. The extra revenue is due to an increased shift away from high price wholesale/imbalance market periods, as exposure to imbalance prices increases the expected price differential between periods, particularly at weekends and in the peak season (see Figure 8). For the CM business case, introduction of capacity price signals from the capacity market has a more significant impact, producing a large increase in revenue compared to the baseline case. $64 \%$ of this revenue increase is attributable to the $4,400 \mathrm{~kW}$ provided by the back-up diesel generators available in the district. The remaining $36 \%$ can be attributed to the $2,500 \mathrm{~kW}$ of capacity available from flexible electricity consumption (EHP and electric boilers) and electrical battery storage (see Section 3.1). In the CM business case, there is a marginal decrease in ESO and VAT cash flow compared to the baseline case, as the reward for maintaining increased electricity consumption during capacity market availability periods (to increase the baseline capacity resource) motivates shift from more efficient EHP to less efficient electric boilers. Although the effect is small in the case study, it demonstrates, again, the type of emergent behaviour which can be of interest to affected actors and system regulators/policy makers.

The value of the DNCM business case, which would aim at reducing net electricity demand during times of network stress (e.g., times of peak electricity demand), compared to the baseline case is negligible in this study. This is because the retail price signals already act to penalise any increase in net electricity demand during the time of peak electricity consumption through the differential between peak and off-peak import and export prices (see Table II). Therefore the opportunity to violate N-1 distribution network capacity is not useful under a cost minimisation objective. This situation may change if, under wholesale market price optimisation, energy prices are so variable that they encourage a shift to low cost periods, creating a new, larger peak at that time.

The UoS business case is expected to produce an increase in revenue compared to the baseline case, as peak demand is reduced from $2710 \mathrm{~kW}$ to $2030 \mathrm{~kW}$ (not depicted for brevity), which reduces UoS cost. Consideration of all business cases and relevant price signals results in the highest increase in revenue compared to the baseline case, largely due to revenue from the capacity market. The contribution of the UoS and electricity price signals is also clear. Thus there are revenue increases from capacity and wholesale/imbalance markets, as well as from UoS fees. This last case demonstrates the significant value that having the flexibility to pursue different cases can have for the district, as well as the attractive capability of the proposed methodology to handle multiple (sometimes conflicting) business cases simultaneously.

\subsection{Value mapping: 'All' price signals business case example}

Figure 11 shows the effect of business case exploitation on the other actors in the system, informed by the connections shown in Figure 7. The 'All' price signals case is taken as an example. Figure 11 clearly demonstrates the power of the mapping methodology as a tool for quantifying the impact of any transactive energy business case on other system actors. Further the ability to differentiate between the cash flows from different commodities/services enables actors to understand the sensitivity of their total cash flows to variation in the revenue from constituent cash flow components. In the demonstrated case study, the increases in operational revenue experienced by the district, compared to the baseline case, come largely at

\footnotetext{
${ }^{4}$ Demand is strongly correlated with electricity price in this particular district, as the magnitude of uncertainty decreases as demand decreases.
} 
the expense of the electricity producer. This is because reductions in district imbalance results in less balancing electricity revenue for the electricity producer, and capacity provided by the district is assumed to be abstracted from the electricity producer. The EDNO can also expect to lose (operational) revenue compared to the baseline case as the district reduces its peak import (on which UoS is charged). It should be highlighted that, as a regulated party with an allowed revenue set by the relevant regulator, a change in operational revenue will only serve to change UoS fee structure (in future years), to ensure allowed revenue is recouped.

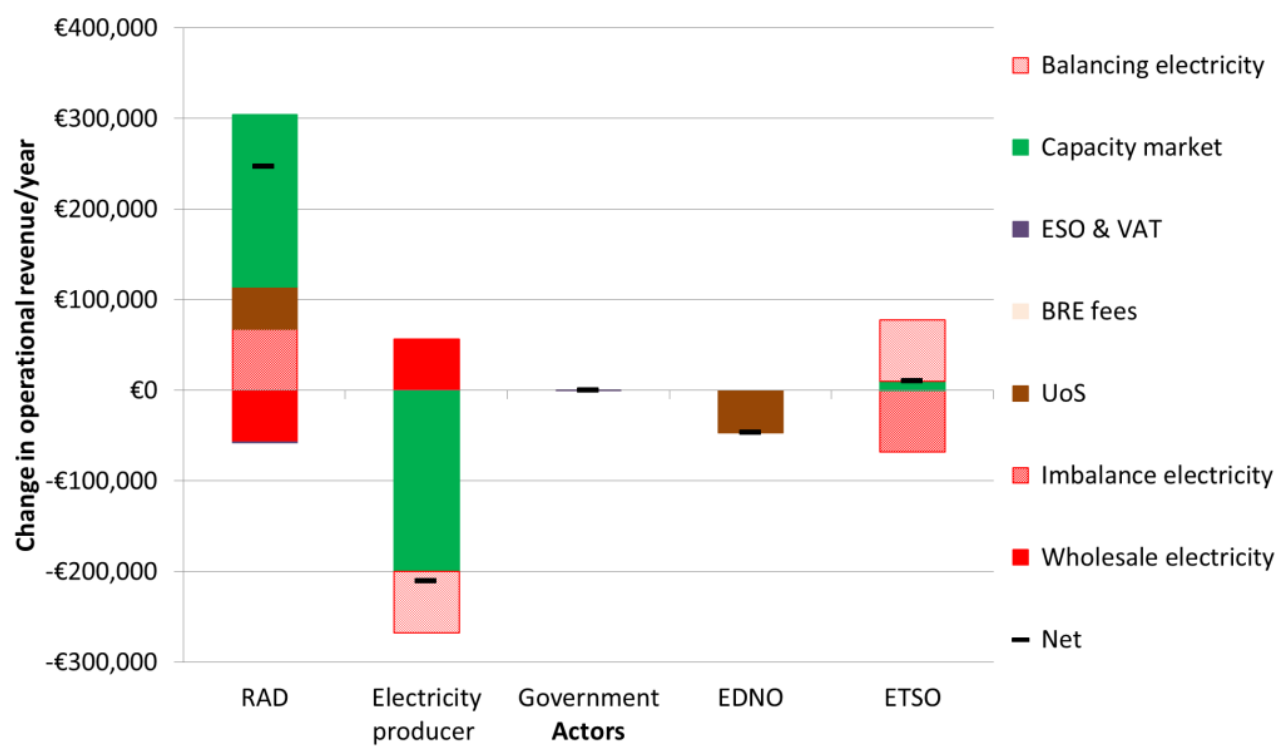

Figure 11: Change in operational cash flows - 'All' price signals case compared to the baseline case, by actor

\subsection{Profit sharing}

For the retailer-aggregator led option, district profit shares of 20\%,50\% and $80 \%$ were considered. Figure 12 shows how the retail tariff varies, by district profit share and by business case, including the baseline case. As shown, the tariff varies little for most cases, as the total profits from business case exploitation are low for most cases, as is the change in electricity consumption (which affects the retailer profit margin, and hence the tariff, as described in Section 2.3), see Figure 12. The exceptions are the CM and 'All' cases, where the more substantial revenue from flexibility exploitation results in significant profit to be shared with the consumer, resulting in lowered tariffs. These cases demonstrate the ability of the profit sharing model to determine tariffs which can serve to share profit between a retailer-aggregator, which is active in markets, controlling and exploiting district flexibility through transactive exchanges, and the passive district consumers. A point of note is the possibility of business case exploitation resulting in higher energy consumption, as flexible plant is utilised to shift grid electricity consumption to lower price periods, incurring thermal/electrical losses, as thermal storage and electrical batteries are utilised to achieve this. Such increases in energy consumption are demonstrated in Table VI. This serves to highlight the non-equivalence of energy and cost optimisation under variable prices. The resulting change in revenue for the consumer, for the various profit share options, is shown in Figure 13.

Also shown in Figure 13, is the change in operational revenue for the consumer led option. In this option all profit accrues to the consumer. As, in all cases, including the baseline case, the retailer service fee (see Section 2.3) does not change, change in district revenue is the same as the change in overall RAD revenue (see Figure 10).

On the basis of these operational cash flow splits, it may be expected that the district will always favour the consumer led option. However, consideration of only operational cash flows ignores other salient factors, such as those relating to investment, as discussed in Section 4.4 . 


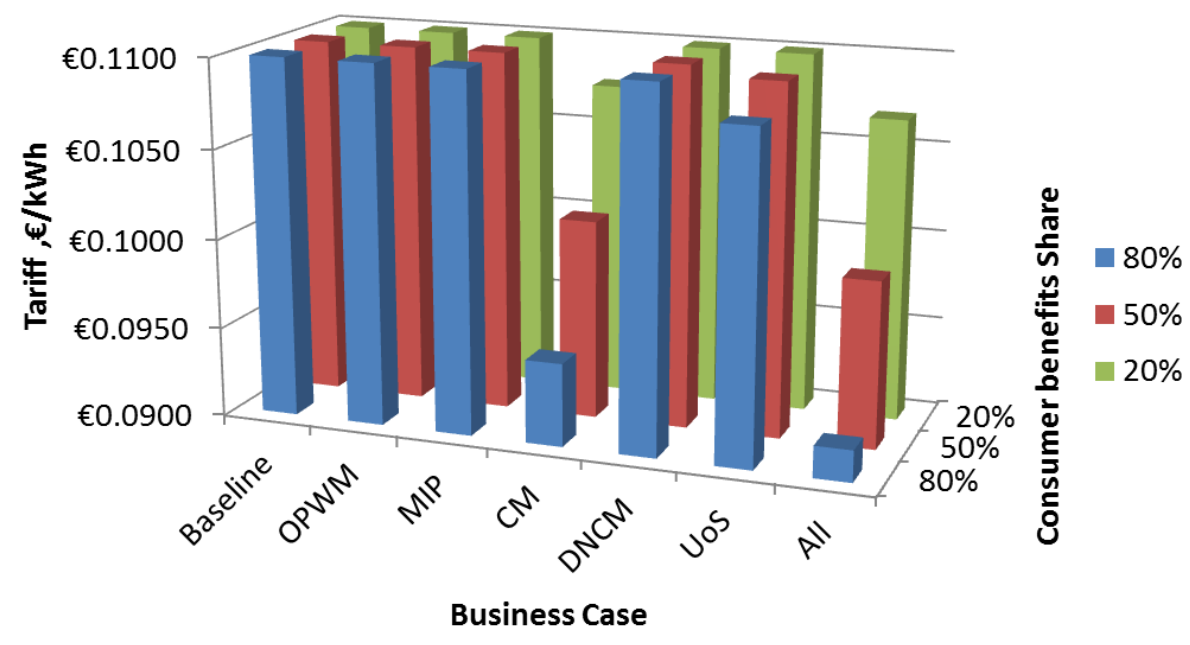

1

Figure 12: Consumer tariffs, by business case

Table VI: Energy consumption, by case

\begin{tabular}{|l|l|l|l|l|l|l|l|}
\hline & & & & & & & \\
Business case & Baseline & OPWM & MIP & CM & DNCM & UoS & All \\
\hline District energy consumption, MWh & 9,304 & 9,310 & 9,310 & 9,342 & 9,304 & 9,302 & 9,315 \\
\hline
\end{tabular}

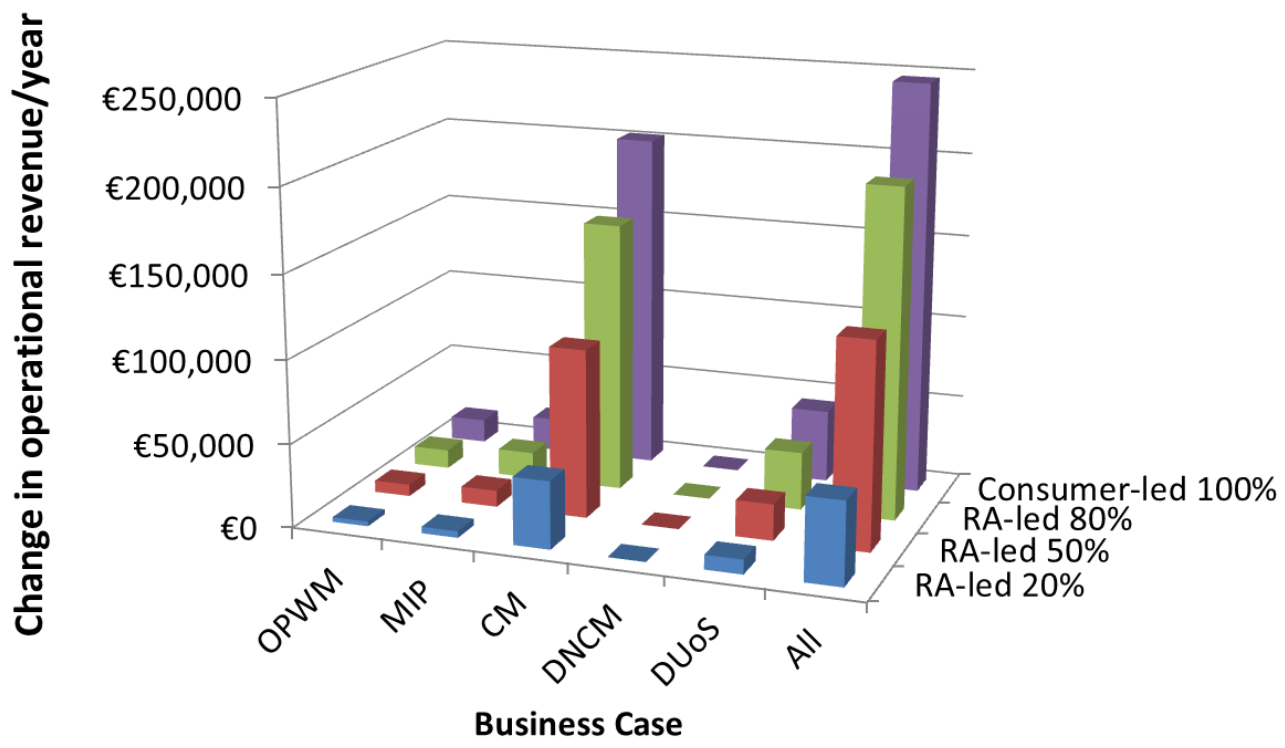

4

Figure 13: District net cash flow for various profit shares and various business cases compared to the baseline case, consumer and retailer-aggregator (RA) led options

\subsection{Economic assessment}

For the considered case study, the only investment required, for all business cases, is for enabling ICT, such as communication, automation and computation devices, which provide the "smartness" required for the studied business cases. No plant investment is required, as all plant was already in place in the baseline case. Given the uncertainty on the level of investment required, and hence business cases, this section considers only the NPV 
of the various business cases, without any ICT investment, for the lead actor. This provides a threshold for the discounted cost of ICT investments, above which the investment can be deemed unattractive. The appropriate discount rate is dependent on the riskiness of the project and the cost of capital, for the actor in question. To reflect the smaller size of the district (compared to the retailer-aggregator), which results in less ability to handle risk and higher cost of capital, the consumer discount rate is taken as $10 \%$, whilst the retaileraggregator discount rate is taken as $7 \%$.

Figure 14 shows the NPV (without ICT investment) for the different business cases for the lead actor, for the four sharing agreements considered. Given the greater operational revenues, the supremacy of the CM and 'All' business cases is unsurprising. Of interest, though, is that the consumer-led case has only marginally more value for the consumer than the retailer-aggregator led $80 \%$ case does. This demonstrates the effect of having a lower discount rate for the retailer-aggregator. Indeed, given the marginal difference between those two cases, the district may well prefer to take part in a retailer-aggregator led scheme, rather than lead their own scheme. This might be the case if the district is particularly risk averse, or if they find the cognitive effort or the administrative burden associated with leading their own scheme excessive. This situation may be exacerbated if ICT investment is substantial, particularly if the retailer-aggregator is able to exploit economies of scale to buy ICT at lower prices.

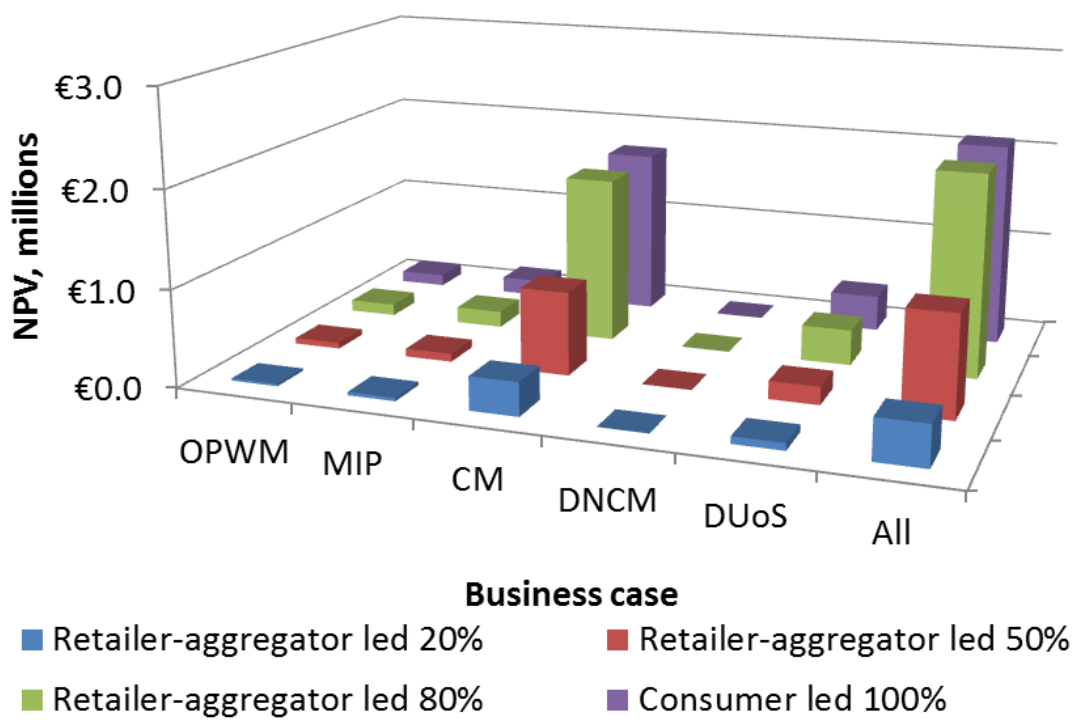

Figure 14: NPV for a 20 year payback period - various business cases compared to the baseline case

\section{Conclusions}

This paper presents a novel and powerful modelling and assessment framework for assessment of business cases for DMES in a transactive energy context, with especially important application to smart energy districts. The framework incorporates an aggregation mapping methodology that can be incorporated into relevant multi-service price-based optimisation models, with tools for dealing with the complexity of the energy system and of profit sharing between commercial partners, as well as for economic assessment. The aggregation mapping approach within the optimisation model provides a flexible and scalable means of modelling various scenarios of physical and virtual aggregation. This may prove useful for quantifying potential benefits of physical aggregation (through electricity, gas and/or heat networks, if applicable) and/or virtual aggregation (through coordination of districts), for example, taking advantage of the diversity of demand, in each case. The modular and extensible graphical mapping methodology enables clarity by clearly specifying the transactive exchanges between actors, mitigating the complexity of energy system demand-side interventions and enabling the impact of any business cases to be clearly quantified. The profit sharing model provides a tool for 
dividing business case benefits between a retailer-aggregator and consumer, dependent on the identity of the 'lead' actor in exploitation of district flexibility. These features offer a concise and powerful framework which enables relevant parties to understand, clearly and quantifiably, the effect on their cash flows of any business case. Use of the framework is demonstrated through employment on a study of several business cases for a smart energy district in the French context. The case study demonstrates both the potentially significant effects of development and optimisation of smart energy districts, but also the power of the described methodology to identify and present such effects with clarity.

The described method has significant implications as a tool for initial business case assessment for both those implementing a business case, and those who may be affected by its implementation. Further, the described methodology can be applied in the design of energy system regulation, and in tax regime design. With respect to regulatory design, the introduced mapping method can offer a means to assess the impact on all system actors of various business models. Additionally, the proposed mapping method can be useful for policymakers to investigate the effect of possible feedbacks that a change in policy might produce, to reduce the likelihood of perverse outcomes. Equally, an actor may employ the method to forecast whether a business model that initially seems acceptable may be at risk from either changes to regulation (i.e., a "regulatory response", such as UoS rate increase, in response to lower UoS fee receipts), or changes in the behaviour of a liberalised actor (i.e., a "market response").

Further work of interest can naturally follow from exploitation of the modular and extensible nature of the value mapping approach. Extension may be vertical (to "upstream" activities, such as gas production; or "downstream" to exchanges within the district), horizontal (considering other energy commodities, such as fuel oils or hydrogen). Further extension may be to consider incentives for low carbon heat/electricity generation, or consideration of large scale and novel, local carbon markets. Indeed investigation of exchanges between the various constituent parts of the RAD (retailer, aggregator and district), under various ownership scenarios, is currently being undertaken by the authors.

\section{Acknowledgments}

The authors wish to acknowledge the funding from the EU Commission under the FP7 COOPERATE (Grant $n$. 600063) and DIMMER (Grant n. 609084) projects, and the H2020 SEAF project (Grant n. 696023), and also from the EPSRC under the MY-STORE project (EP/N001974/1) and thank colleagues in all projects for the helpful discussions.

\section{References}

[1] O'Sullivan J, Rogers A, Flynn D, Smith P, Mullane A, O'Malley M. Studying the maximum instantaneous non-synchronous generation in an Island system-frequency stability challenges in Ireland. IEEE Trans Power Syst 2014;29:2943-51. doi:10.1109/TPWRS.2014.2316974.

[2] Qazi HW, Flynn D. Analysing the impact of large-scale decentralised demand side response on frequency stability. Int J Electr Power Energy Syst 2016;80:1-9. doi:10.1016/j.ijepes.2015.11.115.

[3] Navarro-Espinosa A, Mancarella P. Probabilistic modeling and assessment of the impact of electric heat pumps on low voltage distribution networks. Appl Energy 2014;127:249-66. doi:10.1016/j.apenergy.2014.04.026.

[4] Navarro-Espinosa A, Ochoa LF. Probabilistic Impact Assessment of Low Carbon Technologies in LV Distribution Systems. IEEE Trans Power Syst 2015:1-12. doi:10.1109/TPWRS.2015.2448663.

[5] Daryanian B, Bohn RE, Tabors RD. Optimal demand-side response to electricity spot prices for storage-type customers. IEEE Trans Power Syst 1989;4:897-903. doi:10.1109/59.32577.

[6] Moreno R, Moreira R, Strbac G. A MILP model for optimising multi-service portfolios of distributed energy storage. Appl Energy 2015;137:554-66. doi:10.1016/j.apenergy.2014.08.080.

[7] Mancarella P. MES (multi-energy systems): An overview of concepts and evaluation models. Energy 2014;65:1-17. doi:10.1016/j.energy.2013.10.041.

[8] Good N, Karangelos E, Navarro-Espinosa A, Mancarella P. Optimization Under Uncertainty of Thermal Storage-Based Flexible 
Demand Response With Quantification of Residential Users' Discomfort. IEEE Trans Smart Grid 2015;6:2333-42. doi:10.1109/TSG.2015.2399974.

[9] Althaher S, Mancarella P, Mutale J. Automated Demand Response From Home Energy Management System Under Dynamic Pricing and Power and Comfort Constraints. IEEE Trans Smart Grid 2015;6:1874-83. doi:10.1109/TSG.2014.2388357.

[10] Pavić I, Capuder T, Kuzle I. Low carbon technologies as providers of operational flexibility in future power systems. Appl Energy 2016;168:724-38. doi:10.1016/j.apenergy.2016.01.123

[11] Papadaskalopoulos D, Strbac G, Mancarella P, Aunedi M, Stanojevic V. Decentralized Participation of Flexible Demand in Electricity Markets-Part II: Application With Electric Vehicles and Heat Pump Systems. IEEE Trans Power Syst 2013;28:3667-74. doi:10.1109/TPWRS.2013.2245687.

[12] Drysdale B, Wu J, Jenkins N. Flexible Demand in the GB Domestic Electricity Sector in 2030. Appl Energy 2015;139:281-90. doi:10.1016/j.apenergy.2014.11.013.

[13] Martínez-Ceseña EA, Good N, Mancarella P. Electrical network capacity support from demand side response: Techno-economic assessment of potential business cases for small commercial and residential end-users. Energy Policy 2015;82:222-32. doi:10.1016/j.enpol.2015.03.012.

[14] Good N, Ellis KA, Mancarella P. Review and classification of barriers and enablers of demand response in the smart grid. Renew Sustain Energy Rev 2017;72:57-72. doi:10.1016/j.rser.2017.01.043.

[15] Nolan S, O'Malley M. Challenges and barriers to demand response deployment and evaluation. Appl Energy 2015;152:1-10. doi:10.1016/j.apenergy.2015.04.083.

[16] Good N, Mancarella P. Modelling and assessment of business cases for smart multi-energy districts. PSCC, Genova: 2016.

[17] Six D, Martínez-Ceseña EA, Madina C, Kessels K, Good N, Mancarella P. Techno-economic analysis of Demand Response. In: Losi A, Mancarella P, Vicino A, editors. Integr. demand response into Electr. Chain challenges, Oppor. Smart Grid Solut., Wiley-ISTE; 2015, p. 296.

[18] ENA. Demand Side Response Shared Services Framework Concept Paper. 2014.

[19] Nguyen DT, Negnevitsky M, Groot M De. Pool-Based Demand Response Exchange - Concept and Modeling. IEEE Trans Power Syst 2011;26:1677-85. doi:10.1109/TPWRS.2010.2095890.

[20] EURELECTRIC. Flexibility and Aggregation Requirements for their interaction in the market. 2014.

[21] Capuder T, Mancarella P. Techno-economic and environmental modelling and optimization of flexible distributed multigeneration options. Energy 2014;71:516-33. doi:10.1016/j.energy.2014.04.097.

[22] Mancarella P, Chicco G. Real-Time Demand Response From Energy Shifting in Distributed Multi-Generation. IEEE Trans Smart Grid 2013;4:1928-38.

[23] Sciarretta A, Guzzella L. Control of hybrid electric vehicles. Control Syst IEEE 2007;27:60-70. doi:10.1109/MCS.2007.338280.

[24] Daniell R. Creating the right environment for demand- side response : next steps. 2013.

[25] Pfenninger S, Hawkes A, Keirstead J. Energy systems modeling for twenty-first century energy challenges. Renew Sustain Energy Rev 2014;33:74-86. doi:10.1016/j.rser.2014.02.003.

[26] Hall S, Roelich K. Business model innovation in electricity supply markets: The role of complex value in the United Kingdom. Energy Policy 2016;92:286-98. doi:10.1016/j.enpol.2016.02.019.

[27] Watson J. Co-provision in sustainable energy systems: the case of micro-generation. Energy Policy 2004;32:1981-90. doi:10.1016/j.enpol.2004.03.010.

[28] Sauter R, Watson J. Strategies for the deployment of micro-generation: Implications for social acceptance. Energy Policy 2007;35:2770-9. doi:10.1016/j.enpol.2006.12.006.

[29] Qi W, Shen B, Zhang H, Shen ZJM. Sharing demand-side energy resources - A conceptual design. Energy 2017;135:455-65. doi:10.1016/j.energy.2017.06.144.

[30] Eid C, Bollinger LA, Koirala B, Scholten D, Facchinetti E, Lilliestam J, et al. Market integration of local energy systems: Is local energy management compatible with European regulation for retail competition? Energy 2016;114:913-22. doi:10.1016/j.energy.2016.08.072.

[31] Kulkarni AA. Games and teams with shared constraints. Philos Trans R Soc A 2017;375. doi:10.2307/1911749.

[32] The Gridwise Architecture Council. GridWise Transactive Energy Framework. 2015.

[33] Good N, Martínez-Ceseña EA, Zhang L, Mancarella P. Techno-Economic and Business Case Assessment of Low Carbon Technologies in Distributed Multi-Energy Systems. Appl Energy 2016;167:158-72. doi:10.1016/j.apenergy.2015.09.089.

[34] Rahimi FA, Ipakchi A. Transactive Energy Techniques: Closing the Gap between Wholesale and Retail Markets. Electr J 2012;25:29-35. doi:10.1016/j.tej.2012.09.016.

[35] Liu X, Mancarella P. Modelling, assessment and Sankey diagrams of integrated electricity-heat-gas networks in multi-vector district energy systems. Appl Energy 2016;167:336-52. doi:10.1016/j.apenergy.2015.08.089.

[36] Martínez-Ceseña EA, Good N, Mancarella P. Energy Efficiency at the Building and District Levels in a Multi-Energy Context. Energycon, Leuven: 2016. 
for multi-service demand response. IEEE Trans Smart Grid 2017; In Press.

2 [38] Gordijn J, Akkermans H. Business models for distributed generation in a liberalized market environment. Electr Power Syst Res 2007;77:1178-88. doi:10.1016/j.epsr.2006.08.008.

4 [39] Rte. Imbalance settlement price 2015. http://clients.rte-france.com/lang/an/visiteurs/vie/mecanisme/histo/prix.jsp (accessed

[40] Rte. Mecanisme de capacite: Guide Pratique 2015:23.

7 [41] ERDF. Tarif d'Utilisation du Réseau Public de Distribution d'Électricité. 2014.

8 [42] Martínez-Ceseña EA, Mancarella P. Distribution Network Reinforcement Planning Considering Demand Response Support. 